\title{
OUT OF THE BINARY: WHAT TRANS ADULTS WITH 'EATING DISORDERS' WANT FROM HEALTHCARE PROFESSIONALS
}

\author{
by \\ Zachary Sera Grant, B.A., Trent University, 2008, S.S.W., George Brown College, 2010, \\ B.S.W., Ryerson University, 2019 \\ An MRP \\ presented to Ryerson University \\ in partial fulfillment of the \\ requirements for the degree of \\ Master of Social Work \\ in the program of \\ Social Work
}

Toronto, Ontario, Canada, 2020

(C) Zachary Sera Grant, 2020 


\section{AUTHOR'S DECLARATION}

I hereby declare that I am the sole author of this MRP. This is a true copy of the MRP, including any required final revisions.

I authorize Ryerson University to lend this MRP to other institutions or individuals for the purpose of scholarly research

I further authorize Ryerson University to reproduce this MRP by photocopying or by other means, in total or in part, at the request of other institutions or individuals for the purpose of scholarly research.

I understand that my MRP may be made electronically available to the public. 


\title{
ABSTRACT \\ OUT OF THE BINARY: WHAT TRANS ADULTS WITH 'EATING DISORDERS' WANT FROM HEALTHCARE PROFESSIONALS
}

\author{
Master of Social Work, 2020 \\ Zachary Sera Grant \\ Social Work, \\ Ryerson University
}

This is a qualitative research study using Community-Based Participatory Action Research to explore the healthcare experiences of trans individuals with 'eating disorders'. This research provides recommendations to healthcare providers with the aim of improving the healthcare experiences of trans individuals with 'eating disorders'. Recommendations consist of listening to service users, healthcare providers needing to educate themselves on trans health and 'eating disorders', sharing this knowledge with coworkers; incorporating learnings into personal practice as well as professional workplaces and disciplines; moving beyond your own understanding of the world, unpacking ones biases and practicing reflexivity, allowing trans individuals to make their own healthcare decisions, and transition can assist 'eating disorder' recovery. 


\section{ACKNOWLEDGEMENTS}

To my colleagues of the MSW program - What a ride! When we met in orientation a year ago, we knew we were undertaking a difficult and challenging journey. Yet many of us could not fathom just what we were in for. We struggled, succeeded, found joy, shed tears, learned how to disagree, be vulnerable, and work together. We discovered a new and confusing world when covid-19 changed our lives. I cannot express my gratitude to you all.

To the Ryerson MSW faculty \& staff - There aren’t words to fully express my thanks to you all. To my MRP supervisor Ken Moffatt, thank you for your guidance and faith. To Jennifer Poole, thank you for calling me Dr. Zac - Your belief in this kindergarten drop out has changed my life. I would not be starting my $\mathrm{PhD}$ in the fall without all of your support. To June Yee, I asked you to push me and you always did, I am a better academic because of you. To May Friedman, you always made time for me and taught me to always work towards doing better. To Purnima George, thank you for sharing your love of research and igniting that same passion for research in me. To Notisha Massaquoi, I cannot thank you enough, your mentorship will never be forgotten. To Funke Oba, thank you for all the knowledge you have shared and for offering me learning opportunities. To Chris Chapman, thank you for all the time you spent answering questions and offering guidance and words of encouragement. To Milene Santos Costa Ferreira, you are incredible!

To my roommate and cosmic sibling - Sena. Thank you for listening to all my ideas at all hours of the day. Thank you for your feedback, support, \& love, and thank you for wearing your headphones while I was writing :) To Julie, Jamie, Emily, \& Sam, thank you for listening, editing, and distracting me. To the Taoist Tai Chi Society and its members, thank you for sharing the Taoist arts with me. It has allowed me to find balance in all areas of my life. 


\section{DEDICATION}

To all the Trans, Queer, and Mad Folx who exist in the world - You are needed in this world!

I know the journey is not always easy. I hope we all find community and safer spaces as we work against transphobia, homophobia, sanism, white supremacy, and all forms of oppression.

I wish you all whatever it is that you need.

To everyone who participated in this research, I can't thank you enough. Without your willingness to share your experiences with me, this would not exist.

To those of you who thought about participating but didn't feel as though you were in a space to engage in this research - thank you for taking care of yourself. 


\section{TABLE OF CONTENTS}

Abstract

Chapter 1- Introduction

Chapter 2 - Literature Review

Chapter 3 - Theoretical Framework

Chapter 4 - Methodology

Chapter 5 - Findings/Analysis

Chapter 6 - Implications

Chapter 7 - Conclusion

Appendices

Reference List
Page iii

Page 1

Page 10

Page 21

Page 26

Page 34

Page 50

Page 59

Page 61

Page 67 


\section{LIST OF APPENDICES}

Appendix A - Checklist for PAR with Transgender Communities

Appendix B -Application of CBPR Principles in the TTFN Project

Appendix C - Survey Questions
Page 61

Page 62

Page 63 


\section{CHAPTER 1. INTRODUCTION}

"I'm not trans enough." "I'm not eating disordered enough." "I don't have a diagnosis, so everything's ok."

These words are spoken by people in a variety of bodies, their life circumstances differing in every way imaginable except, despite their statements, these individuals have chosen to access support for trans folx1 who self-identify as having an 'eating disorder'2.

Their words have grown to haunt me over the last few years. It is common for individuals struggling with their body shape, size and relationship with food and exercise to feel as though their 'eating disorder' is not valid. The media bombards us with images of emaciated young, white, cisgender3 women when discussing 'eating disorders'. Many of the people I work with express their frustrations with these images and messages as they do not see themselves reflected in media portrayals of 'eating disorders', making it that much harder for them to validate their own experiences. They are not made to feel as though their experiences are real.

When I decided to start medically transitioning, a few of my friends and members of my healthcare team made statements including, "I guess you won't be sick anymore since boys don't really have "eating disorders"'. This speaks to how family and friends of individuals with "eating disorders' are witnessing these same media depictions. Individuals with 'eating disorders' often feel invalidated further when their support network fails to recognize the possibility of their lived

1 Folx: alternative spelling of the word folks which "incorporates the $\mathrm{x}$ that is being widely used to bring in more identities to conversations, such as womxn, latinx, and alumx to name a few. In keeping with the intention of allowing folx an identity outside of the [gender] binary" (Robertson, 2018).

2 In an attempt to acknowledge hegemonic psychiatric language, the term 'eating disorder(s)', as well as all psychiatric labels will be contained within single quotations.

3 Cisgender: individuals who identify with the gender assigned to them at birth (Mizock, Harrison, \& Russinova, 2014, pg. 324). 
reality. We know that people of all gender identities and expressions can experience 'eating disorders', yet these dominant narratives perpetrate oppression and can increase suffering. Unfortunately, as with my own experience, the erasure and invalidation of one's experience is not limited to one's social circle, often healthcare providers fall victim to dominant 'eating disorder' narratives as well. In Canada, “70\% of doctors receive 5 hours or less of eating disorder-specific training while in medical school" (Girz, 2014). Equally concerning are the results of a 2004 study which found that "only $6.3 \%$ of psychiatry residents felt they had spent enough time with [eating disorder] patients to work effectively with them in clinical practice" (Williams \& Leichner, 2006). These findings highlight why medical doctors may have little more understanding of 'eating disorders' than the average individual.

The reality is even more concerning when combined with the fact that the majority of research on 'eating disorders' only includes cisgender women's experiences. In 2016, Cohn, Murray, Wallen and Wooldridge, found that in Eating Disorders: The Journal of Treatment and Prevention (EDJTP), 54\% of the articles referring to prevention were in relation to cisgender females, 39\% included information on cisgender males, while none of the articles discussed transgender and/or non-binary identities (Cohn et al., 2016). EDJTP, in their 2019 "Updates in the Treatment of Eating Disorders" explores areas requiring further study. While the editors acknowledge the dominant whiteness of 'eating disorder' studies and encouraged diversity, this did not extend to gender although all studies reported in the journal only made mention of cisgender women and men (Murry, 2020). To date, I am aware of only a few 'eating disorder' studies that include trans people. Of the three studies that include nonbinary participants, two are published (Duffy, 2016; Simone, 2020) and one is unpublished (Pinelli, 2019). 
Further complicating trans individuals' experiences seeking healthcare for 'eating disorders' is the knowledge that "statistics from 11 Canadian medical schools show a median of 4 hours spent in pre-clinical education on lesbian, gay, bisexual and transgender (LGBT) topics" (Yan, 2015). In conversations with friends who are healthcare providers, very few of them received any training that specifically focused on trans health or even included trans individuals when discussing best practice for service delivery. My own social work training over the last decade has only recently discussed the possibility of working with trans clients outside of mental health-related training.

I believe colonization, transphobia, sanism, and fatphobia are the underlying issues at play contributing to this exclusion. I don't believe these are necessarily conscious acts perpetrated by hateful aggressors, but rather that these oppressions (transphobia, sanism, fatphobia) are perpetrated and maintained through conscious and unconscious colonial acts that

we are all implicated in. Unfortunately, the consequences of engaging with colonial systems and societies may cause great harm beyond our comprehension. My hope is that this study works against this oppression by naming it and encouraging readers to continue educating themselves about all the ways in which we are implicated by colonialism. I encourage readers to think beyond their own understanding and knowledge of the world and to contemplate the possible ramifications of our actions.

\section{A Note on Language Used in this Study}

For myself, I have attempted to use language thoughtfully throughout this study as a way of contemplating the effects of its use on a larger scale. Language is a complex and complicated tool. Often, we may not give much consideration to particular terms, however, this study ascribes to an anti-sanist and Mad studies informed, Decolonial theoretical framework which understands 
that there is power in the act of naming (Smith, 1999). Semiotics acknowledges that naming through the use of language not only legitimizes and makes real but creates criteria as to what something is and is not (Hall, 2000). As noted above, dominant media messages of 'eating disorders' manifest a definition that neglects a variety of embodiments. The intentional framing of 'eating disorder(s)' within quotations, acknowledges that this term may not be preferable to all participants, due to its roots in psychiatry, but is utilized as a means of addressing an already named socially acknowledged phenomenon.

For the purpose of this study the term 'eating disorder' represents not only a diagnostic category within the Diagnostic and Statistical Manual of Mental Disorders (DSM) (APA, 2013), but also refers to a phenomenon outside of psychiatry which may or may not constitute a site of struggle and distress (even when meeting criteria for a diagnosable disorder). This definition reflects my experiences working with individuals with 'eating disorders' and is supported by literature. It recognizes that individuals can struggle with 'eating disorder' symptomatology without meeting medical criteria for a disorder (Gaudiani, 2019); while also creating space for individuals who understand their 'eating disorder' outside of psychiatry and may not view it as a site of struggle.

Similarly, I use the term trans more holistically, as an umbrella term to describe “individuals whose gender identity or experience is different, discontinuous, or more complex than the gender assigned to them at birth" (Hanssmann, 2008), this may include individuals who identify with some of the following labels: transgender, transsexual, agender, nonbinary, gender diverse/ independent/ nonconforming/ questioning, or individuals who identify within the binary of male and female but who identify differently to the gender assigned to them at birth. At the same time, we should be cautioned that this list is not exhaustive. 


\section{A Note on Whiteness}

Massaquoi (2015) states that queer or LGBTQ2S+ infers whiteness. That "the use of the term queer is based on a particular historical experience and many marginalized communities have limited if any historical connection with the term (Walcott, 2006 as cited in Massaquoi, 2015, p. 768). Therefore, we need intersectionality in our approaches as a way of reducing the oppression that continues to permeate throughout social justice movements and as a way of acknowledging the multiple identities that coexist within these complex terms and labels (Massaquoi, 2015). I think it is important to remember that often the term 'eating disorder' also implies whiteness. Through my research I attempted to find 'eating disorder' literature that moved beyond whiteness. While this proved difficult, Nalgona Positivity Pride (NPP) is one organization that is designed specifically for non-white individuals with 'eating disorders' (Lucas, 2020).

NPP is an in-community eating disorders and body-positive organization dedicated to creating visibility and resources for Black, Indigenous, communities of color (BICC.) Since 2016, NPP has been raising awareness around the specific needs of BICC through digital media, education, grassroots eating disorders treatment models, and art. Rooted in Xicana indigenous feminism and DIY punx praxis, NPP emerged out of a great need not only to shed light on the experiences and barriers that exist in BICC affected by bodyimage and troubled eating but to create opportunities of healing by and for BICC (Lucas, 2020).

The founder of NPP, Gloria Lucas writes extensively on why this intersectional work is needed.

It is known that EDs [eating disorders] are manifestations of trauma and weight stigma however, when marginalized communities experience non-stop violence due to racism it is difficult to stop messy coping mechanism... When you continuously carry the stress of potentially getting killed by police it is hard to heal. This is why ED harm reduction is imperative to the wellbeing of [BICC] communities that lack resources (Lucas, 2020).

Janani Balasubramanian (2014), a queer, South Asian performance and literary artist writes about the impact of this implied whiteness in relation to 'eating disorders'. 
I remember being hugely troubled by the language many of the speakers and health educators would use about their experiences: that 'eating disorders were about power and control, not beauty'. As if this were a dichotomy. As if beauty were something other than a system of control and domination. There is nothing shallow about beauty; I have drowned in it. My anorexia had everything to do with affluent white womanhood, something not available to me, but that I was systemically surrounded by. It had everything to do with heterosexuality: an aspiration for 'proper and dignified' white womanhood - that is ultimately desirable to white masculinity. (Balasubramanian, 2014).

I want to recognize that decolonial work and interrogating white supremacist capitalist patriarchy (hooks, 2014) is a continual practice. Even as a member of communities facing marginalization, I will likely not get this all right, even as I locate myself within the intersection of this research. Instead I have chosen to take a harm reduction approach. I will do my best with what I know and continually work to do better. In this way, I cannot assume that I will ever reach a point of fully knowing. It holds me accountable to continually interrogate the current literature and my understanding of this research, while holding myself accountable to doing better and acknowledging that my understanding of the world is founded in white supremist capitalist patriarchy (hooks, 2014), despite my social location.

\section{Locating Myself}

As a white settler, trans individual with a history of an 'eating disorder', a social service worker currently facilitating 'eating disorder' support groups, and a graduate level social work student, I'm sure it is easily understood why I have come to study the healthcare experiences of trans individuals with 'eating disorders'. Not only is this topic personal, but it affects so many of the people I care about and work with. Without fail, every week as I sit in a variety of settings, personal and professional, myself or colleagues, clients, and caregivers share heartbreakingly challenging and problematic experiences they have faced while interacting with healthcare providers. 
While it is easy for me to commiserate, empathize, and provide support, I am always left with the understanding that, while my actions are necessary, it does little to address the systematic nature of the situation at play. The reality is that there are a variety of factors working simultaneously, resulting in the problematic medical experiences of trans individuals with 'eating disorders'. My goal is not to place blame, but rather to identify areas of improvement and practical strategies. My intent in life, as well as in my social work practice and research, is to always 'do better'. This means acknowledging when I do not know, doing my best to find an answer, and holding myself accountable for my behaviour, while furthering my education.

\section{Moving into The Research}

I have spent the last 12 years working within the field of mental health and addictions. While I love the variety of my work, I have always had a special interest in 'eating disorders'. For years I had been frustrated by the lack of 'eating disorder' supports in Toronto and Ontario at large. Even when I managed to find 'eating disorder' supports for my clients, they often could not afford to pay out of pocket for services, or would refuse to access what was available because they did not feel as though they were welcomed by other participants due to their marginalized identities. Two years ago, I realized that if I did not start advocating for change and creating some of the 'eating disorder' services my clients wanted, they may never exist. With this realization, I began to approach 'eating disorder' services, advocating for change. Within a few weeks, I was offered a space to begin facilitating a weekly 'eating disorder' support group for trans, nonbinary, and gender questioning folx.

Since beginning this work, I have often been approached by cisgender therapists and parents who ask me to provide education focusing on the unique experiences of trans individuals with 'eating disorders'. It is amazing that these people are reaching out to further their 
understanding. Unfortunately, all too often, trans individuals with 'eating disorders' are forced to educate their own healthcare professionals, during their own appointment time, about the basics of 'eating disorders' and trans identities. I do not believe that any individual should have to provide education while accessing services designed to provide support to them.

Much of my support work with trans folx centers around how to speak with healthcare providers. It also involves providing educational resources designed for healthcare providers, so that service users don't have to spend their time self-advocating and educating. At a basic level, when healthcare providers are uninformed on trans healthcare and 'eating disorders', it increases the burden on the service user while conveying the message that trans health is unimportant or an afterthought.

I have chosen to focus on the healthcare experiences of trans people with 'eating disorders' as a way to highlight what is important to trans people with 'eating disorders' when receiving healthcare. At the same time, I hope to contribute to the movement focused on knowledge that is created by members of the communities being researched (Pyne et al., 2017; Travers et al., 2013). As a trans identified individual who has had previous personal experience with eating challenges, and who also currently works within eating disorder support, I believe my insider/outside knowledge (Savvides, 2014) will prove beneficial to the research and will help facilitate systemic change. My unique set of experience provides insight into the complexities of navigating and interacting with the healthcare system from the perspective of a service user and healthcare provider. It also affords me insight beyond my own experiences into the realities of working as a helping professional with service users who identify with a variety of gender identities who also identify as having an 'eating disorder'. 
This MRP will begin by discussing the relevant literature on 'eating disorders', mental health, and trans individuals. I will then discuss the theoretical frameworks I utilized. From there I will move into a discussion of community-based participatory action research (CBPAR) and how it was used in this study. I will then discuss the findings of this research and its implications for social work. 


\section{CHAPTER 2. LITERATURE REVIEW}

\section{Mental Health, Trans Folx and 'Eating Disorders': A Complicated History}

Trans identities and 'eating disorders' exist as both mental health diagnoses within a psychiatric framework, and as personal identities more broadly. Psychiatry utilizes the DSM as well as the International Classification of Diseases (ICD) as tools to categorize and define mental disorders (Burstow, 2015; Mills, 2014). There is much debate within psychiatry and Mad spaces around the usefulness and legitimacy of the DSM and ICD as evidence-based tools (Burstow, 2015; LaMarre, 2020; Mills, 2014). Many Mad, Consumer Survivor, and Anti-Psychiatry activists and nonactivists highlight the unscientific nature of the DSM as well as its colonial, Eurocentric bias. These biases allow diagnoses to be used as a tool of oppression and control (Burstow, 2015; LaMarre, 2020; Mills, 2014).

In 1980, the American Psychiatric Association (APA) added Gender Identity Disorder (GID), the incongruence of one's gender assigned at birth and one's gender identity causing distress, to the DSM-III (Tosh, 2017, p. 255). In 2013, DSM-5, renamed GID to Gender Dysphoria (Tosh, 2017, p. 256). The ICD classified Gender Incongruence as a 'mental health disorder' until May 2019 when the World Health Organization (2020) voted to reclassify it under the title 'Sexual Health', however this change will not officially be recognized until January 1, 2022 (n.d.).

In the context of psychiatry, both the DSM and ICD classify feeding and 'eating disorders' as mental disorders (Claudino et al., 2019) but this is just one accepted view. In my social work practice, as well as in my personal life, individuals often disclose difficulty with food and exercise using the label 'eating disorder', although they do not have an official diagnosis made by a qualified healthcare provider. Sheena's Place in Toronto, which provides 
'eating disorder' support free of charge utilizes a broader definition of 'eating disorder' which includes anyone who is struggling with disordered eating or body image even if they do not have a DSM diagnosis (n.d.). They have chosen to take this approach as it allows individuals to access support without having to engage with the medical system in order to receive a diagnosis. Throughout history and still true today, as medicine, particularly psychiatry, has been a source of oppression for many individuals (Burstow, 2016). It also fosters a more wholistic approach which allows individuals to explore if 'recovery' is right for them, while not limiting 'recovery' to a medicalized definition.

Many people who identify as having an 'eating disorder' have shared how challenging it is when they finally decide to access support only to be met with disbelief as they do not meet the very strict DSM criteria. This is especially important as we know that when someone is not believed, is told their struggles are not 'bad enough', or does not receive the care they need, they may not try to access help again (Romanelli et al., 2018, p. 832). Unfortunately, we know that often times accessing help is how one receives a diagnosis. When individuals are unable to receive a diagnosis, their experiences are often then de-legitimized both clinically and publicly, however holding a diagnosis is also stigmatizing (LaMarre et al., 2020, p. 67). What further complicates this reality is that systemic barriers such as race, sex, sexual orientation, gender, ability, inform clinical perceptions which determine who is seen as worthy of a diagnosis (LaMarre et al., 2020, p. 67). Receiving a diagnosis may be advantageous, however "attracting a label may invite bodily surveillance and treatment modes that are incongruous with folks' orientation to the world, and to their health" (LaMarre et al., 2020, p. 67).

As the above statement suggests, mental health diagnoses are often seen as something one either has or does not have. Jennifer Poole (2015), a professor at Ryerson's School of Social 
Work, challenges her students to look at mental health diagnoses as something that can happen to anyone - It is not if you have mental health but rather when. Poole's point is that mental health stuff can come and go based on our circumstances, rather than something that is inherent within us. That Madness is emotion, and what is so problematic about embracing our emotions? (Poole, 2014). LaMarre et al. (2020) suggests that not only is mental health more fluid than psychiatry would have us believe, but that individuals' experiences of mental health might not be validated as such by the medical model. This can leave many individuals with intersectional identities not understood by western medicine struggling to find resources where their experiences will be validated.

A large percentage of scholarly articles discussing trans and/or individuals with 'eating disorders' make reference to additional mental health labels beyond GID and 'eating disorders'. I believe many authors do this as a way of acknowledging the implications of transphobia on trans individuals or what psychiatry would call "minority stress" (Meyer, 2003). We know that individuals who experience discrimination can experience poor mental health, which increases one's risk of being labeled with multiple 'psychiatric disorders' (Tosh, 2017). Trans individuals who experience transphobia in a way that impacts their access to basic needs - nutrient rich food and clean drinking water, safe affordable housing, positive social supports, feelings of worth and value, inclusive knowledgeable healthcare, meaningful employment, and education - are at an increased risk of mental health challenges and diagnosable mental disorders (Kirby, 2014). However, many articles only mention the increased phenomenon of poor mental health among trans people while neglecting the impact of systemic oppression which is most likely responsible for these increased rates of multiple psychiatric labels (Kirby, 2014). 
I would ask if it is ethical for psychiatry to perpetuate this notion that trans individuals are somehow inherently predisposed to brain abnormalities (Ault \& Brzuzy, 2009). The dominant discourse surrounding the cause of psychiatric disorder has been brain abnormality; despite the fact that "no biological sign has ever been found for any 'mental disorder'... and there is no known physiological etiology" (Burstow, 2015, p. 75). Many trauma specialists believe that what is often labeled as psychiatric disorder is actually a response to trauma (Clark et al., 2017). Some Mad scholars would agree with trauma specialists, while others may understand it as just 'normal life' (Gorman, 2013).

Interestingly, Bonnie Burstow, a Mad scholar and activist, points out that the DSM's definition of 'mental disorder' itself, complicates the notion that trans individuals are inherently 'mentally unwell';

A Mental Disorder is a syndrome characterized by clinically significant disturbance in an individual's cognition, emotional regulation, or behaviour that reflects a dysfunction in the psychological, biological, or developmental process underlying mental functioning... An expectable or culturally approved response to a common stressor or loss such as the death of a loved one, is not a mental disorder. (American Psychiatric Association, 2013, p. 20, as cited in Burstow, 2015, p. 84)

If we acknowledge that trans individuals experience expectable stressors as a result of transphobia, then we can no longer suggest trans individuals are at increased risk for 'mental disorders'. For this reason, the diagnosis of GID should be challenged altogether

because its symptoms primarily embody a conflict between individuals and their society - a violation of APA's own standards for diagnosis - and because of the internal paradoxes and inconsistencies in the structure of the diagnosis and its treatment implications for children and adults (Ault and Brzuzy, 2009, p. 189).

Keeping in mind the DSM's definition of 'mental disorder', we can begin to understand the perspective of Mad scholars and activists who view psychiatry as a colonial tool furthering the oppression faced by many marginalized groups. It would appear that trans individuals are 
only labeled with additional 'mental disorders' because their "culturally approved reactions to stressors" (American Psychiatric Association, 2013, p. 20 as cited in Burstow, 2015, p. 84), cannot be read as normal when trans identities are pathologized and seen as unnatural. I believe that it is imperative to keep this in mind as we navigate the healthcare experiences of trans individuals with 'eating disorders'.

The DSM-5 defines an 'eating disorder' as "a persistent disturbance of eating or eatingrelated behavior that results in the altered consumption or absorption of food and that significantly impairs physical health or psychosocial functioning” (APA, 2013, p. 329). 'Pica', 'rumination disorder', 'avoidant/restrictive food intake disorder', 'anorexia nervosa', 'bulimia nervosa', and 'binge-eating disorder', are all classified as 'eating disorders', 'other specified feeding and eating disorders' is listed as a separate category, which applies to presentations in which symptoms characteristic of a feeding and eating disorder that cause clinically significant distress or impairment in social, occupational, or other important areas of functioning predominate but do not meet the full criteria for any of the disorders in the feeding and eating disorders diagnostic class. (APA, 2013, pp. 353)

There is a great deal of literature related to 'eating disorders' and 'eating disorder' treatments, with the majority of research focusing on white cisgendered women (Gaudiani, 2019; Tabaac, 2018). While some literature explores cisgendered men's experiences of eating disorders (Pinelli, 2019, pp.17), a small body of literature examines lesbian, gay, and bisexual individuals experiences of eating disorders (Watson, 2017), with very little research examining the experiences of trans individuals with 'eating disorders' (Duffy, 2016; Pinelli, 2019). With much of the existing literature consisting of either of case-studies (Hiraide et al., 2017; Donaldson et al., 2018; Ewan, 2014), or specifically focuses on trans youth (Coelho et al., 2019; Guss, 2016). Three exceptions to this are works by Pinelli (2019), Duffy, Henkel, and Earnshaw (2016), and 
Simone, Askew, Lust, Eisenberg, and Pisetsky (2020), who explored trans adults' experiences of 'eating disorder' recovery and treatment.

In 2018, the Trevor Project completed the first national survey of LGBTQ youth in the United States, in partnership with the National Eating Disorder Association. Results found that " $54 \%$ of LGBTQ youth had been diagnosed with an eating disorder, with an additional $21 \%$ suspected they had an eating disorder. In comparison, $71 \%$ of transgender youth who identified as straight had been diagnosed with an eating disorder" (p. 4). Academic literature also supports claims that trans individuals experience high levels of eating disorders and eating distress (Duffy, 2016; Coelho et al., 2019). Diemer and colleagues (2015) found that transgender college students were more than 4 times more likely to self-report an eating disorder diagnosis than cisgendered women.

It is important to highlight that both these studies are American, however I believe Canadian findings would be similar. While I believe these numbers capture the distress many trans individuals may be experiencing, these numbers may increase if we take into consideration the tendency of trans individuals to avoid medical professionals due to previous negative and oppressive experiences (Bauer et al., 2015) as well as critiques of the strict criteria of DSM-5 eating disorder diagnoses which only capture distress after a particular threshold (Gaudiani, 2019 , p. 10), combined with the tendency for eating disorder diagnostic tools to cater towards cisgender women (Stanford, \& Lemberg, 2012).

\section{The Inadequacy of Healthcare for Trans Folx}

There is a consensus among both trans individuals and healthcare providers that healthcare is failing trans individuals. A growing body of research has explored the health care experiences of trans individuals (Anzani, 2019; Goldberg, 2019; Ross, 2018). This research tends 
to be divided into two groups, trans individuals experience of healthcare (Meyer, 2019; Travers et al., 2013), and healthcare professionals' understanding of the barriers faced by trans individuals (Hanssmann, 2008; Israel, Walther, 2011).

Current studies have highlighted the lack of education and training on trans issues for healthcare providers (Hanssmann, 2008), biases and stereotypes held by healthcare providers towards trans individuals (Diamond \& Kirby, 2014; Tosh, 2017) and the pathologization of trans individuals by healthcare providers (Stroumsa, 2019). While some studies have attempted to address these barriers by providing best practices for healthcare providers (Hanssmann et al., 2008), other studies have focused on collecting data on trans individuals in order to prove the need for improved healthcare for trans people (Travers et al., 2013).

Coutin, Wright, and Fung (2018) found that most endocrinology and psychiatry residents felt that trans-care was included in their scope of practice, while " $71 \%$ of family medicine and $50 \%$ urology residents agreed", however, only " $17 \%$ of all participants felt they would be competent to provide trans-care at the end of their residency" (p. e45). Stroumsa et al. (2019) found that increasing education on trans healthcare was not enough, as pre-existing biases and transphobia by primary care providers informed their knowledge of trans healthcare more than formal education.

While it is clear that healthcare needs to improve in relation to trans health, it is also clear that healthcare providers do not feel as though they have access to the information that they require to provide proper care. Additionally, it appears that we must find a way to get healthcare providers invested in learning about trans healthcare. While this study may not be able to address both these concerns, I am hoping it will provide healthcare providers with some of the 
information they need to better inform their practice, resulting in more positive interactions for the trans folx who may access their services.

\section{The Role of Social Workers}

"Social workers are an integral part of an effective health care team and are one of the top three professionals accessed by clients in the mental health care system after general practitioners and psychiatrists" (Towns \& Schwartz, 2012, as cited in Petruik et al., 2017, p. 339). All healthcare practitioners, including social workers, need to be able to work with a variety of individuals from varying social locations. As such, we have a duty to continue our training beyond the limited scope covered in our academic training. It also means that as social workers, we are in a unique position to assist not only our clients but other healthcare providers through the identification of service gaps. Social workers can combine this with advocacy for change at a broader societal level.

The Canadian Association of Social Workers (CASW, 2005) code of ethics lists, "Respect for Inherent Dignity and Worth of Persons Value, the Pursuit of Social Justice Value, and Service to Humanity" (CASW, 2005) as the first three values of Social Work. These values require that social workers do not discriminate against their clients for any reason or tolerate discrimination towards their client from others (CASW, 2005). It would also suggest that Social Workers have a duty to work towards social justice in their interactions with other healthcare practitioners.

Mulé (2015), highlights that since social justice is imperative to social work practice in Canada, social workers need to consider how to incorporate social justice at all levels of practice (p. 37). In relation to macro structures, we need to make sure that policies are created with trans individuals in mind. For Mulé (2015), when policies and social service agencies "absent LGBT 
people from named inclusion in health and social care policy it wilfully releases them from being accountable to LGBT people's social and health issues, needs and concerns" (p. 35). Therefore, we as social workers,

need to advocate not only for their inclusion, but also for the receipt of social and wellbeing benefits that will generate a more sustainable level of service provision that would rightfully address the numerous, complex, ongoing, broad health issues, needs and concerns of LGBT people and redress the precarious health service provision currently available to LGBT people in Canada. (Mulé, 2015, pp. 37)

Even social workers working at a micro or mezzo level must challenge dominant oppressive discourses about gender, since service users will bring issues to individual counselling that are caused by systemic oppression (Ault \& Brzuzy, 2009).

Maegusuku et al. (2015) explore how systemic issues, such as limited funding towards 'eating disorder' programing can lead to service users being left waiting with little communication about where they are on lengthy treatment waitlists or the length of time they may be expected to wait for treatment, these experiences often cause distress for service users. For Maegusuku et al. (2015), it is not enough to support a client, we as healthcare practitioners need to highlight that lengthy waitlists are not supported by "evidence and good practice guidelines that advocate early effective treatment to be crucial in longer-term physical and emotional health (Wales NHS, 2012 as cited in, p. 85). As social workers, we can work for additional funding, increased program creation, and additional communication between supports and service users.

Nadal et al. (2010 as cited in Kia, 2016) have found that service users experience numerous micro-aggressions when accessing healthcare, in addition to systemic barriers. These micro-aggressions consist of;

(1) use of terminology that overtly discriminates against sexual and gender minorities; (2) endorsement of hetero- and gender-normative culture and beliefs; (3) referring to the 
experiences of LGBTQ people as being homogenous or unidimensional; (4) exoticization of LGBTQ microaggressions (e.g., using LGBTQ people for comedic relief); (5) discomfort with visible expressions of non-heterosexuality such as same-sex displays of affection; (6) denial of the reality that LGBTQ people experience discrimination on the basis of their sexual and/or gender identities; (7) pathologization or oversexualization of LGBTQ individuals; and (8) denial of individual experiences of discrimination among sexual and gender minorities. (p. 811)

In response to these micro-aggressions Kia et al. (2016) have made several recommendations for social workers to consider when working with LGBTQ2S+ service users. These include practitioners developing awareness around LGBTQ2S+ language used by service users (p. 818); an "openness toward discourses used by [LGBTQ2S+] clients to challenge and resist systems of domination" (p. 819); "validating the feelings of victimization that LGBTQ2S+ clients may be left with after encountering experiences of microaggression in health and other social service settings" (p. 819); prioritizing "the voices and language preferences of service users, recognize that their experiences hold the greatest salience in determining service needs, and honour their autonomy in decision-making to the extent possible" (p. 819); the development of partnerships "with community-based agencies or collectives advocating for the needs and rights of sexual and gender minorities" (p. 820); the initiation of

research whose objectives specifically reflect the development of insight into microaggressions, as well as marginalizing effects of such violence, on LGBTQ individuals, and in turn use this knowledge base to develop practice guidelines on preventing and addressing these behaviours across contexts of service provision (p. 821);

"actively using the existing evidence base on LGBTQ microaggressions as a vehicle for justifying structural change aligned with the mitigation of such violence” (p. 821).

Petruik et al. (2017) also discuss the importance of self-reflection or a reflexive practice for social workers. A willingness to examine one's own discomfort and reactions to challenging situations while working towards growth and change are seen as imperative to good social work practice (Petruik et al., 2017, p. 341). For Oba (2018) "use of self is important for the social 
worker in practice as well as in research to enhance reflective deconstruction" (p. 86). For both Oba (2018) and Petruik et al. (2017), reflexivity allows social workers to uncover systemic barriers that impact service users in a way that also uncovers how they themselves are also implicated in systemic oppression in their practice. 


\section{CHAPTER 3. THEORETICAL FRAMEWORKS}

\section{Theoretical Approaches and Methodologies: Maintaining the Status Quo}

This study acknowledges that engagement with colonial systems perpetuate oppression, we must not forget that research methods and theoretical approaches themselves are often constructed within colonial systems. Much of the literature, including research claiming to be critical, has neglected to address this reality. Hunter (2002) would argue that theorizations grounded in pathologization of certain communities only maintains the status quo and hence cannot be understood as coming from a critical paradigm. Thus, any studies that are steeped in psychiatric discourse (unfortunately a large number of both 'eating disorder' and trans healthcare experience studies) are therefore rooted in positivism, despite claims that they are critical.

Much of the literature perpetuates the very oppression it claims to work against by stating facts about trans individuals mental health as if it is inherently true, when they continue to use hegemonic language without unpacking it, and when they ignore diversity within trans and 'eating disorder' communities. Audre Lorde (1984), famously wrote, "the master's tools will never dismantle the master's house". While I recognize that within academia, we are required to use the 'master's tools', I believe we can begin to dismantle the 'master's house' by at least acknowledging the impact that these 'tools' have on our society. Returning to a previous statement I made, my goal is to constantly 'do better' - I believe if we all want to 'do better' we must acknowledge our role in the perpetuation of oppression, hold ourselves accountable, and continue our work while consistently implementing new ways of engaging with 'the masters tools'. 


\section{Mad Studies and Decolonial Theory: An Intersecting Framework}

To understand decolonization, we must understand colonization; Waziyatawin (2008)

defines colonization to be "by its very nature, antithetical to justice. Therefore, complete

decolonization is a necessary end goal in a peaceful and just society. This would entail

overturning the institutions, systems, and ideologies of colonialism" (pp. 13 as cited in Peterson

\& Chatterjee, 2017, pp. 139-40). Decolonization is political (Tuck \& Yang, 2012). For

Indigenous peoples and communities decolonization is a way of "processing multiple losses,

from land to language, culture to place in the world" (Brown et al., 2012, as cited in Peterson \&

Chatterjee, 2017, p. 140).

Decolonization... is a process of discovering the truth in a world created out of lies. It is thinking through what we think we know to what is actually true. ... [The] truth is the main struggle, and the struggle is manifest mainly inside our heads. From there, it goes to our families and our communities and reverberates outward into the larger society, beginning to shape our relationship with it.... our struggle is with all existing forms of political power. (Alfred, 2005, as cited in Oba, 2018, p.197)

Tuck and Yang (2012) state that,

decolonization brings about the repatriation of Indigenous land and life; it is not a metaphor for other things we want to do to improve our societies and schools. The easy adoption of decolonizing discourse by educational advocacy and scholarship, evidenced by the increasing number of calls to "decolonize our schools," or use "decolonizing methods," or, "decolonize student thinking", turns decolonization into a metaphor. As important as their goals may be, social justice, critical methodologies, or approaches that decenter settler perspectives have objectives that may be incommensurable with decolonization. (p. 1)

It is imperative to recognize that as Tuck and Yank (2012) state, this research is not truly decolonial but rather operates as more of a decentring of settler colonialism. It would be detrimental to believe that this study is based in true "Indigenous sovereignty and futurity" (Tuck \& Yang, 2012, p.35). 
Mad studies emerged from Mad activism (Morrow, 2017). The term "Mad comes from outside of medical and scientific discourse [as an identity it] might be based on self-or community-defined histories and experiences, rather than on medical diagnoses" (Gorman, 2013, p. 269-70). Madness as a possible identity, beyond psychiatric understanding, allows for individuals to interpret their experiences in multiple ways, beyond psychiatric discourse, allowing for psychic difference to move "beyond the narratives of diagnosis, trauma, and escape. It became possible to narrate these moments in relation to my awareness of being mixed race" (Gorman, 2013, pp. 276).

Mills (2017) reminds us that it is imperative to remember that colonialism and psychiatrization are distinct but have a complex interconnected history. This is being acknowledged more and more as Mad scholars begin to acknowledge and explore how psychiatry has been utilized as a colonial tool (Daley, 2013; Ibrahim, 2017; Mills, 2017; Peterson \& Chatterjee, 2017). Nandy, (1983 as cited in Mills, 2014), unpacks this complexity in a simple way - colonialism creates a culture where some individuals may want to rebel, colonialism solves this issue through the creation of psychological limits by defining what is sane and rational, thereby discrediting anyone who attempts to rebel (p. 142). When Madness engages a decolonizing lens, it exposes how psychiatry has been used to prevent different populations from engaging in activism or activities leading to social unrest (Tam, 2013, p. 295).

Liegghio (2013) views psychiatry as epistemic violence which disqualifies Mad folx by classifying them as incompetent and dangerous, very similar to racist colonial systems. For Liegghio (2013), this erasure of being can only be corrected by "bringing psychiatrized people back into existence" by offering a Mad framework which operates outside of psychiatrization (p. 127). Going further, Mills (2014) suggests that by reminding people that they have the right to 
non-medical intervention, even when experiencing distress, acts as a very reminder that alternatives to psychiatry do exist, even though they are often "actively demonized" or “eclipsed" by dominant psycho-pharmaceutical approaches" (p. 141).

This would suggest that employing a decolonial Mad framework involves expanding what is possible beyond dominant discourse. Actively engaging in political discourse that works for social justice. Acknowledging power and how it operates through social relations based on one's race, gender, sexuality, class, ability, ethnicity, and age (Morrow, 2017, p. 47). It involves highlighting how colonialism and psychiatry uses 'naming' to maintain control by turning 'on the recognition and disavowal' of difference (Mills, 2014, p. 142). It means refusing to perpetuate colonial practices, moving beyond "what counts as 'sane' and what counts as evidence" (Mills, 2014, p. 142).

While I have attempted to decolonize this research, the reality is, I continue to draw on ontological constructs that continue to perpetuate a Western, white settler, academic activist dominated research study. Categories create treatment practices which may not align with one's needs or wishes, with "often unsatisfying solutions to distress" (LaMarre, 2020). Utilizing social justice informed Mad (Burstow, 2016; Diamond, 2014; Kirby, 2014; Pyne et al., 2017) and decolonial (Clark et al., 2013;2017; Ibrahim, 2017; Mills, 2014; Morrow; 2017; Peterson \& Chatterjee, 2017; Sarkar, 2020) scholarship to inform this study while there is a plethora of literature focusing on trans communities and mental health, only some of this literature acknowledges the pathologization of trans individuals by the psychiatric and medical system (Kirby, 2014; Pyne et al., 2017; Tosh, 2017). As such, I have chosen to utilize a technique discussed by Bonnie Burstow (2016) - 'unhooking' my language from dominant oppressive psychiatric discourse. This involves exploring alternative language to that of 'eating disorder' 
and other psychiatric labels. It also involves fluidity in my definition of terms. I have chosen to utilize a more accessible definition of eating disorder which encompasses a "wider range of embodiments and behaviours around food", exercise and body image, beyond psychiatric discourse (LaMarre, 2020). 


\section{CHAPTER 4. METHODOLOGY}

\section{Community-Based Participatory Action Research}

This is a qualitative research study using CBPAR (Katz-Wise et al., 2019; Pyne et al., 2017; Travers et al., 2013), to explore the healthcare experiences of trans individuals with 'eating disorders'. The research provides recommendations to healthcare providers, with the aim of improving healthcare experiences of trans individuals with 'eating disorders'. Participants were asked not only to focus on past or current healthcare experiences, but to also consider what healthcare providers could do differently to support trans individuals who self-identify as having 'eating disorders' when accessing healthcare.

For the purpose of this study, CBPAR was chosen as it aligns with my values and beliefs; believing it is important to begin with the communities involved and build on existing strengths and resources, while fostering community collaboration, and working towards social change (Roche, 2011). CBPAR is founded in critical social science and believes neutrality cannot exist within research (Wallerstein \& Duran, 2017).

Based on a philosophy of partnership and principles of self-determination, equity, and social justice, [CBPAR] aim[s] to break down barriers between the researcher and the researched (Cornwall \& Jewkes, 1995) by assuming that people are able to assess their own needs and to act upon them (Minkler, 2004; Minkler \& Wallerstein, 2003) and by valuing community partners as equal contributors to the research project (Minkler, 2004). (as cited in Maiter, 2008)

CBPAR does not assume the needs of the community but rather allows the community to determine its own needs, approaches, and solutions by working with research participants (also known as co-researchers) at all stages of the research process (Kemmis et al., 2014). Many scholars view CBPAR as the superior method when conducting research with marginalized communities as it empowers marginalized communities to produce research based on the needs of the community (Furman, 2019; Tebbe \& Budge, 2016). 
CBPAR allows for greater participant control and input at various stages of research, which is imperative for marginalized communities who may be distrustful of research (KatzWise et al., 2019; Pyne et al., 2017; Travers et al., 2013; Wagaman at al., 2018). It is congruent with this research with its commitment to social justice which inspires to create research which benefits the communities being studied (Katz-Wise et al., 2019; Pyne et al., 2017; Travers et al., 2013; Wagaman at al., 2018).

Although I identify as trans and as having an 'eating disorder', I wanted to utilize CBPAR as a way of acknowledging and keeping in the forefront, that my own experiences are not the same as others. I believe I must continually remind myself of this as well as the overall goal of the research - to create positive social change. I believe this involves being reflexive and continually checking in with myself around my actions and research decisions (Baksh, 2016; Sky, 2016). I must continually recognize that although I identify as a member of the communities I am researching, I do not hold the same social locations, experiences, and identities as others within these communities. Therefore, I must make room for competing knowledges and differing opinions.

Reason (1994, p. 334 as cited in Healy, 2001, pg. 96) notes that while Participatory Action Research (PAR) requires the research to come from the communities being studied, "paradoxically, many PAR projects could not occur without the initiative of someone with time, skill and commitment, someone who will almost inevitably be a member of a privileged and educated group. PAR appears to sit uneasily with this.' Healy (2001) goes on to note that, The view that participation emerges in the absence of [a] researcher...[fails] to acknowledge the positive or negative operations of researcher power in PAR... As Phillips (1991: 134) observes, 'Power that is acknowledged can be subjected to mechanisms of democratic control; power that is denied can become unlimited and capricious.' (p. 97) 
While I as a researcher initiated this particular research, the research question itself came out of my participation in support groups for trans individuals with 'eating disorders'. While my research is founded in CBPAR, due to time limitations, true CBPAR could not truly be accomplished. Nonetheless, I have made sure to include community members at all stages of this research, from its conception to data analysis, and dissemination.

\section{My Role in this Research}

True CBPAR requires that a research committee is formed with members from the community being studied (Healy, 2001; Katz-Wise et al., 2019; Singh et al., 2013). As mentioned, due to time constraints of this study, I was unable to set up an official committee. However, since I am known in both trans and 'eating disorder' communities, I had many people reach out, wanting to discuss this research and be a part of it in a variety of ways. This is how I included community members in the research beyond the role of research participant.

It was through conversations with community members that led to a change in how I would participate in this research. Originally, I had no intention of completing the survey myself. I had decided that I would simply bring my own experiences into the larger MRP and in the formulation of the research. Some community members understood this reasoning and others suggested that I might complete the survey so that I could experience what it felt like. It would also serve as methodological rigour.

I agreed to complete the survey myself. I waited a month after the creation of the survey, to complete my responses, as a way to maintain some distance. I attempted to only address my actual experiences and not discuss any of my research. Even after completing the survey myself I was unsure if I would include my own responses along with the other participants. After 
completing the survey, I was glad I was able to have that experience. It was emotional and provided me with some context to the feedback I had received from other participants.

After many conversations with community members, I have decided to include myself as one of the research participants. I have made a conscious decision to highlight the experiences of the other participants over myself. I had been concerned that my responses would vary from the other participants. Through data analysis, I realized that many of my own responses mirrored what was being said by other participants. Although there were commonalities amongst all responses, I must highlight that there were unique and surprising findings from all participants.

\section{Creation of the survey}

I utilized work by Singh, Richmond, \& Burnes (2013) and their checklist for participatory action research with transgender communities (see Appendix A) to guide the overall research process. Not only did it provide a framework for how to engage in Participatory Action Research, but it required me to "assess my own intersecting identities... and identify how [my own] personal liberation is connected to the liberation of [my] informants and participants with whom [I] work" (Singh et al., 2013, p. 97). I also utilized Katz-Wise and colleagues' (2019), Application of Community-Based Participatory Research Principles in the TTFN Project

(see Appendix B). Which asks researchers to "address health from both positive and ecological factors" (Katz-Wise et at., 2019, p. 190). These guides acted as reminders to continually be reflexive and transparent, while also continually engaging with communities affected by this research (Katz-Wise et al., 2019; Singh et al., 2013).

Research questions were developed by the researcher in collaboration with other trans individuals who identify as having 'eating disorders' and were informed by personal knowledge, blog posts, and existing research. These questions were compiled into an online survey (Kemmis 
et al., 2014) created using Google Forms. The survey contained 36 questions, 7 questions focusing on participant demographics, 6 questions regarding the sharing of the research results, 5 yes or no questions, and 24 long answer questions (see Appendix C).

Research began at the end of March, once ethics approval had been obtained. Participants were recruited through social media posts on Facebook and by reaching out to the National Eating Disorder Information Centre (NEDIC), which "provides information, resources, referrals and support to Canadians affected by eating disorders" (2019). And the National Initiative for Eating Disorders (NIED), which "helps caregivers, patients, and practitioners fill gaps in care through education and by highlighting better practices in prevention, health promotion, and treatment" (2020). Both NEDIC and NIED are located in Toronto, Canada.

While few supports exist specifically for trans individuals with 'eating disorders' Facebook hosts two such support groups, Trans Folx Fighting Eating Disorders (T-FFED), a group whose mission is "to make visible, interrupt, and undermine the disproportionately high incidence of eating disorders in individuals on the trans and gender non-conforming spectrum through radical community healing and recovery institution reform" (2020) and Toronto Trans Folx Eating Disorder Support Network, “a resource for individuals who identify as Trans or Nonbinary, their friends and loved ones... providing accessible eating disorder recovery spaces for Trans communities that recognize the impact our intersectional identities have on our wellness" (2020). Both Facebook groups along with NEDIC and NIED were asked to share the recruitment flyer, as they are prominent 'eating disorder' resources that have relationships with various healthcare professionals who specialize in 'eating disorder' treatment.

Social media was chosen as a means of recruitment as many trans individuals rely on the internet for a sense of trans community (Furman et al., 2019). This is particularly true for trans 
individuals who may live in rural areas, or communities that do not have trans supports, or if trans folx experience high levels of transphobia in the physical world (Travers et al., 2013). CBPAR would ideally advocate for inclusive and fully accessible means of recruitment, however, due to the outbreak of COVID-19 and the relevant physical distancing measures, all recruitment was required to be completed online. Initially recruitment was through posters placed in the community as well as online as a way to engage members of the community who may not have access to the internet.

Individuals who were interested in participating in the research study contacted the researcher by email and were asked if they met inclusion criteria - self-identify within the trans umbrella, self-identified as having an 'eating disorder', accessed healthcare services related to their gender identity and 'eating disorder' or where the healthcare providers they engaged with were aware of their trans and 'eating disorder' identities. Participants were also provided with a digital copy of the consent form to review. Once individuals confirmed that they met eligibility criteria and agreed to participate, the researcher provided them with a link to the online survey.

The survey was completed by a total of 5 research participants. Participants ranged in age from 19-50 years of age. Two participants identified as Trans/Nonbinary/Transmasculine, one participant identified as Trans/Nonbinary, one participant identified as a Transgender man and one participant identified as a Transgender female. Three participants identified as pansexual with one participant identifying as bisexual and one participant identifying as Queer. All participants described their 'eating disorder' as engaging in restrictive eating with 3 participants referring to purging behaviours, three participants referring to exercise compulsions, two referring to 'safe' or 'healthy' foods, and one participant referring to binging behaviours. 
All participants identified as white. While I had hoped that recruitment for this study would include individuals from a range of social locations, including non-white individuals, this study failed at that goal. While I did expect the majority of participants to be white, due to the implicit whiteness of both 'eating disorders' and LGBTQ2S+ mentioned previously, I was surprised to find that all participants identified as white. This is clearly a limitation of the research. It is imperative to keep in mind that all participants identify as white while reading the findings, since it is possible that the findings would be very different had the study included nonwhite, Indigenous, People of Colour.

\section{Data Analysis}

Thematic analysis was used to analyze the data. Coding examined the answers to each specific question as well as overall themes. Attention was paid to participants' emotional, physical, spiritual, and mental experiences as well as positive, neutral, and negative healthcare experiences. Areas of improvement and any suggestions for improvement were also highlighted. As per CBPAR values, participants were also asked questions about the dissemination of the findings.

CBPAR is founded in an understanding that many communities being studied experience historical and ongoing oppression and discrimination (Singh et al., 2013). For this reason, CBPAR requires participants and community members to be included at all stages of the research, while also holding researchers accountable for their actions (Singh et al., 2013). CBPAR also believes in disseminating results beyond academic settings for the purpose of “obtaining feedback on interpretation, as well as increasing knowledge within the community" (Katz-Wise et at., 2019, p. 190). To do this, participants were asked, if they would be comfortable with the results being shared beyond this MRP; if they had any concerns sharing the 
research results beyond this MRP; if there were things I could do as the researcher to reduce their concerns when sharing the results; and what format they would prefer to see the research results disseminated and why (see Appendix C).

All participants responded that they felt comfortable with the results being disseminated beyond this MRP. Participants suggested infographics, posters, websites, pamphlets, newspaper or magazine articles, visual art and other creative mediums, etc., as possible ways to do this "that would benefit the community" (Research Respondent). Infographics were suggested by the most participants and for this reason, an infographic will be created. 
CHAPTER 5. FINDINGS/ANALYSIS

\section{Healing May Happen in Unexpected Places in Unexpected Ways}

When it comes to trans individuals with 'eating disorders', it is clear their needs are not being met by healthcare providers. There is a disconnect from what trans folx with 'eating disorders' need from healthcare and what is being provided. Participants spoke about difficulty finding or accessing care, a lack of awareness by healthcare providers, not feeling heard by healthcare providers, a need for intersectional approaches to healthcare, a focus on prevention rather than on treatment, accessing healthcare as trauma, and creativity within healing.

\section{Difficulty Finding/Accessing Care}

For this study I had defined healthcare providers as a person who provides healthcare service to you. I wanted to acknowledge that healthcare comes in many forms and often exists outside of a western-biomedical model. Although I loosely defined healthcare provider for the context of the study, I wanted participants to define the term, from their own context for this research. Based on participant responses, healthcare providers consisted of dietitians, nutritionists, social workers, primary care doctors, psychiatrists, therapists, endocrinologists, surgeons (including plastic surgeons), occupational therapists, traditional Chinese doctors, chiropractors, naturopaths, registered nurses, massage therapists, and gynaecologists.

For the purpose of this study, I also wanted to know what types of supports participants had accessed if any. Participants shared that they found support or accessed healthcare for both their 'eating disorder' and gender identity from the providers listed above, as well as through 'eating disorder' day hospital and inpatient programs, community nonprofit 'eating disorder' supports, various support groups at local LGBTQ+ centers, psychoeducational programs at hospitals and community programs. Participants also noted that their 
friends and personal support networks were very important, as were books, online support groups, and self-help tools. These are important findings as it shows the variety of supports trans individuals with 'eating disorders' have accessed. What is particularly concerning is that despite accessing multiple supports and modalities, all participants spoke to the lack of inclusive knowledgeable supports. Participant \#1 stated,

I have a lot of difficulty finding folks with knowledge of how transgender health care (e.g. surgery, hormones, psychological challenges) intersects with eating disorderrelated health care. The majority of people I have seen have been willing to research said intersection though.

Participant \#4 described their experience as,

I was wary of seeking someone out because I'm trans. I only took recommendations from my local LGBT center staff, and current weekly therapist. I found a therapist who had experience with TGNC [trans and gender nonconforming] individuals and eating disorders. I still feel my options for healthcare, especially relating to mental health, are limited. I must make sure they have experience with people like me, or at the very least are educated.

Participants were also asked if they had accessed supports designed specifically for trans and nonbinary people. This was to see what supports might be available and if they were meeting the needs of the community. Three participants said they had not but participant \#1 noted that, "If the support was affordable and easily accessible, I would access it".

Of the two participants who have accessed trans and nonbinary specific 'eating disorder' supports, participant \#2 said "I felt out of place due to lack of trans masc[uline] people in the group". This is important to recognize that there is much diversity among trans individuals with experiences of 'eating disorders' and representation within these programs may also be lacking. 


\section{The Relationship Between Gender Identity and 'Eating Disorders'?}

The survey also consisted of questions regarding the relationship between gender identity and their experiences of 'eating disorders'. While most participants described a link between their 'eating disorder' and gender identity, participant \#4 said that "gender identity has little to no impact on my eating disorder. Occasionally, body dysphoria may trigger not wanting to eat/ food avoidant behaviors."

Participant \#5 began their response similarly to participant \#1 by stating, "I think a long time ago I wouldn't have thought about how they [gender identity and 'eating disorder'] relate to each other." However, they went on to elaborate,

When I was receiving [eating disorder] treatment about 6 years ago, I realized there was a link. I wasn't out as trans to a lot of people yet and had had negative experiences when I had disclosed my gender identity... When I started treating my 'eating disorder', my gender was really at the forefront of things I needed to deal with...some of my 'eating disorder' helped me cope with the gendered expectations I had or society had for me - taking care of my spouse, cleaning, cooking, laundry, caregiving ... my 'eating disorder' helped me to be the 'good woman' that I thought I needed to be.... I wasn't ready to deal with the consequences of coming out as nonbinary. (Participant \#5)

While we cannot use Participant \#5's experience as an explanation for all trans folx with 'eating disorders'. Their response provides insight into how our understanding of our experiences may change over time.

Participant \#1 echoed participant \#4's mention of the impact of gender dysphoria stating, "The dysphoria associated with the discordance between my sex assigned at birth and my current gender identity reinforces my body dysmorphia and, in turn, my eating disorder." Participant \#2 also related stating "after being on a path of 'recovery' and gaining weight, the accumulation of weight in my chest caused me to relapse." Participant \#3 described their experience as, 
a way to control changes happening to my body that I hated, i.e. puberty. I got involved with athletics and have been my whole life which was certainly a way to control my body. I may not have liked the way I looked or felt but both athletics and restriction gave me agency over my body the way nothing else did. I mean I think it became a bit of a snake eating its tail scenario because endurance athletics are all about [power to weight ratio] so that certainly fostered restriction as a positive relative to athletic performance.

All participants spoke to a relationship between their body or societal expectations and their engagement with 'eating disorder' behaviour.

\section{Need for Intersectional Approaches to Healthcare}

Participant \#5 mentioned that they had negative experiences after disclosing their gender identity. Other participants spoke to this as well.

I wish I had felt safe to be able to talk to my parents or doctor and tell them that I was, I am, trans. I was filled with such a sense of fear and dread that I just damp it down [for] close to 32 years. I wish that we weren't pathologized as being mentally ill, because we're not. Because this is treatable, to one degree or another. It's not on the medical community to help people come out, that's not what I'm saying, but I am absolutely certain I would have transitioned in my teens if it absolutely felt possible. (Participant \#3)

Other participants highlighted how important it is for healthcare providers to work

from an intersectional approach. "Being allowed to talk with a physician about transitioning and actually doing so, helped alleviate some of the symptoms surrounding my eating disorder" (Participant \#1).

You can't just treat one part of transness or the 'eating disorder', they are intertwined, especially for someone transitioning late...In the case of trans folx it needs to be wholistic, we end up doing most of the work ourselves. If we are lucky enough to have really great friends to support... even in this healthcare system, which is pretty good in Ontario, there is a lot of stuff we carry around and don't share with our physicians. There is a fundamental mistrust of physicians. I don't trust them completely; I don't share everything. I'm not sure they could even help me. (Participant \#3)

Participants also spoke to why an already informed healthcare provider is imperative.

Training regarding eating disorders in the TGNC [trans and gender non-conforming] community is vital. Not only may our symptoms look different, but eating disorders 
affect us in a very different way. Staff training is vital to get us the help we need and show us that we are in a safe environment. (Participant \#4)

Participant \#4 goes on to state the importance for healthcare providers to practice from an informed intersectional approach while also remembering the diversity among trans and nonbinary people. "Our symptoms or "red flags" may be different, and our disorders may or may not be related to our trans identities. Individual analysis and care, as well as knowledge of our identities, is crucial" (Participant \#4).

Participant \#4 then highlights why it is so important for healthcare providers to become more informed about trans and nonbinary people with experiences of 'eating disorders'. 'Educated health services allow us to focus on our recovery better, instead of having to guard ourselves and provide explanations every time” (Participant \#4).

Participant \#5 notes that when healthcare services are not seen as intersectional it can cause harm to individuals whose experiences do not fit within the "normal'. "I didn't know how healthcare providers would handle it [my gender identity] and many weren't trained to. It meant looking for supports in weird places..." For participant \#5, it was only when accessing trans specific 'eating disorder' supports that they felt understood. "We really need more spaces like [trans specific eating disorder support]. That is where I feel heard and validated and my experiences are seen/reflected in other's experiences" (Participant \#5).

Participant \#3 highlighted the importance of intersectionality in healthcare,

I don't recall or think that it was until I started refeeding and dealing with all my bodily functions kicking in again that I even told my doctor that I was struggling with my eating disorder again. So, I guess there was no screening going on that might have alerted them to the fact that I had relapsed.

If healthcare incorporated an intersectional lens to training and/or healthcare providers were able to understand that individuals' social locations impact their experiences, trans and 
nonbinary individuals' experiences of 'eating disorders' might be understood as valid experiences of 'eating disorders'.

\section{Lack of Awareness and Needs Not Being Met by Healthcare}

This lack of support within traditional 'eating disorder' supports was echoed by most participants. Participant \#1 describes how healthcare providers often make assumptions "about how my gender identity and eating disorder manifest", through statements such as "You're transgender and were assigned female at birth, so you must identify as $100 \%$ male"

(Participant \#1). They continue on to say,

I think health care providers should not assume the degree to which one's gender identity and eating disorder do or do not intersect, as this can vary. I think health care providers should have at least a basic knowledge of both subjects, if not more if specializing. (Participant \#1)

Participant \#2 echoed this sentiment and described how other program participants also

played a role in their needs not being met,

Lack of acknowledgement/concern that dysphoria was a factor in ED in questionnaires and focus of groups at [hospital eating disorder program], misgendering by other patients and having to advocate for sharing of pronouns in a place where I was already emotionally exhausted, feeling out of place and scared of making others uncomfortable in an all-female environment, dismissal of trauma that was highlighted because of being in the program, being told to try and remember that I was no longer in the situations I was being intensely reminded of, instead of being given strategies to help, sense that many of the staff didn't want to hear about things about [eating disorder] that didn't fit in their "overvaluation of weight and shape" ED model. Being singled out to share pronouns on first day. (Participant \#2)

Participant \#3 spoke to how healthcare providers have a lack of understanding of "eating disorders' as well as gender identity.

They have an awareness that I am a trans and have an eating disorder and that's really about it. I think if I ever relapsed, they might be prepared to intervene but that's way too late to be of any use. Eating disorders need to be caught before there is a need to intervene.

They went on to say that, 
there is a lot of shit that comes up at various times during transition that require a metric ton of heavy lifting and I feel that the medical community is simply too focused on a 'we'll fix it when it's broke', instead of 'let's work hard to keep the rubber side down'... transition is so complex that access to multiple modalities of care would be fantastic. (Participant \#3)

Not all participants had negative experiences with healthcare providers. Participant \#2 also found that "the social worker at [hospital eating disorder program] assigned to me was very receptive when I told her what I needed to feel more comfortable." While interacting with healthcare providers who are receptive to feedback is important, we must remember that taking time to educate healthcare providers is unpaid labour.

Participant \#3 suggested that,

If health care were proactive, instead of reactive, it would be possible to have better outcomes with people transitioning. You need to work with trans people differently. I shouldn't have to explain why I think I'm trans, especially in a system where informed consent is the law of the land. If I was a doctor and someone walked in and said I'm trans, I would say, ok, here are the options, not prove it, ok, now here are the options. Until there is a broader sense of gender in general, there needs to be a different modality of care for trans people, period.

\section{Accessing Healthcare as Trauma}

As we saw above, many of the participants described their frustrations with the healthcare system and lack of knowledge by healthcare providers. Some participants' experiences were much more concerning. With participants discussing the harm caused by accessing services that were not designed with trans folx in mind.

I've experienced such great harm from [healthcare providers]. I know this is not [their] intent. I've never thought a healthcare practitioner has intentionally hurt me, but the problem is, a lot of you have hurt me unintentionally and I'm not even sure you know you have. (Participant \#5)

Participant \#4 echoed this sentiment stating, "I did not feel safe admitting to doctors about my eating issues, particularly as a trans person." 
Participant \#3 described the dismissal of their experience due to strict DSM criteria.

"The current modalities of care are worse than my eating disorder... there is little that can be done for me because I am currently at a healthy BMI and therefore do not have a 'problem'. Participant \#5 also shared that they, "withheld [eating disorder] from one doctor because I wasn't sure it was relevant, and I didn't want it to impact my ability to access Hormone Replacement Therapy or surgery." This illustrates just how much power healthcare providers hold over the decisions of trans people to transition even though Ontario works under an informed consent model for transition (LGBT Health Program, 2015, p.5).

Participant \#5 continued to elaborate on this when asked, why do you think it is important for health care providers to become more informed about trans and nonbinary people with experiences of 'eating disorders'?

Because we get left out of medical training. We are seen as more problematic and fucked-up when we show up for help and providers aren't aware this is even a thing [eating disorders in trans populations]. It doesn't lead to social justice if I have to spend my entire appointment educating you on trans issues and eating disorders. I hate being the one who is better informed on both topics and it doesn't illicit confidence, especially if you then proceed to tell me how you are going to treat me and help me without going away and doing your homework....we get harmed/hurt when you don't know. We are left to suffer, and we are forced to do things other patients don't have to do... it's more energy we have to spend when we may already be exhausted... you [healthcare providers] are there to help and we need to feel like this is true, we want to have the same experience as other people who access you for support. Because we are thriving and want to continue doing that and we don't need unnecessary barriers. Because we do exist. Because what does that say to us when you don't know. Because it makes it harder to ask for help when we know you don't know. Because we are erased...... and that isn't ok. Because you might learn that this [being a trans person with an eating disorder] isn't always a limitation. Because you might start to see other aspects of your practice differently. Because why not? If you could do better why wouldn't you want to? Because the consequences of not [being informed] can be life or death for some of us. 


\section{Informed Practitioners \& Creativity Help with 'Eating Disorder' Recovery}

While all participants struggled with traumatic experiences while accessing healthcare, some participants spoke to more positive experiences. Participant \#1 describes a good therapeutic relationship, "my first therapist, though predominantly assigned to help with my eating disorder, helped me recognize that the concept of not being 'trans enough' was not reality."

Participant \#2 found that gender affirming healthcare assisted with their 'eating disorder' recovery, "being given a top surgery date gave me hope that I could get to a point where I could stop punishing my body." Participant \#4 explained why they found genderinformed healthcare providers helpful, "seeing an individual who has worked with TGNC [trans and gender non-conforming] individuals in the past is extremely helpful. I don't have to explain my identity, or certain concepts that relate to my community."

Participant \#5 elaborated on how gender informed practitioners/spaces can help and the harm that comes when this isn't provided.

Gender identity stuff helped my [eating disorder] treatment/recovery a lot. It also helped me frame my idea of a masculine and/or feminine body in new ways and helped me escape this gender binary.... being nonbinary meant my body could exist outside of these systems. It gave me freedom that traditional ED recovery didn't. It also was a place I could connect with people who understood what I was going through. I felt heard in a lot of these spaces... some ED practitioners would say to me, "I guess now that you are a boy you won't have an eating disorder anymore". Queer positive spaces helped me navigate stupid statements like that. (Participant \#5)

Some participants spoke to the importance of creativity and gender informed supports

to assist healing, beyond traditional healthcare models.

I am mostly treating my eating disorder myself and with the help of friends who have had similar struggles... I am not receiving medical help for this at present. I am just doing it on my own. (Participant \#3) 
Participant \#5 spoke to how they utilized LGBTQ2S+ language as a way of accurately naming and reclaiming their experience.

[eating disorder label] have always felt the most accurate, but I also have identified as Food Queer in the past because I hate DSM labels. Really labels in general. They don't seem to really capture human experience. (Participant \#5)

\section{What Has Been Helpful}

Participants were asked to describe if there was anything that their healthcare providers do or have done that has been particularly helpful for them as a trans person with an 'eating disorder'. For Participant \#3, the reduction of systemic barriers was imperative.

"Informed consent makes it easy to access Hormone Replacement Therapy and basic medical interventions" (Participant \#3).

For Participant \#1,

The most helpful thing I have experienced is a willingness to admit a lack of knowledge without heavily relying on myself to inform [healthcare providers] on information easy to research (e.g. general concepts regarding dysphoria).

Participant \#5 also spoke to the openness of healthcare providers,

Practitioners who don't necessarily feel like they have to fix you.... [who] understand that accessing formal care may be dangerous and not really an option (as much as they would like it to be one)... they are amazing [so are] the on es who do 'the work' and know what forms should look like and what questions not to ask... they are great.

They continued to say,

My Traditional Chinese Doctor, naturopaths, dieticians, therapists, massage therapist, and chiropractor have all been phenomenal. I actually can't say enough about them. My chiropractor was even at Trans pride last year... I ended up marching with her for a while. I asked if she would make her forms more trans positive and she agreed no questions asked. Even saying she would do it by the end of the week. (Participant \#5)

This illustrates the importance of being open and honest as healthcare providers with service users. As well as the importance of incorporating service user feedback into our healthcare practices. 


\section{What Can Healthcare Providers Do to Help}

Participants were also asked to name what they would like healthcare providers to do specifically when working with trans folx with 'eating disorders'. Below are 9 suggestions for successfully working with trans service users with 'eating disorder' based on participants responses and the thematic analysis above.

\section{Listen and Hear what Service-Users are Actually Saying}

Listening to me and validating that dysphoria was a factor in my [eating disorder].

Trans people know their objective reality best.... Listen. Really listen. That as a coping mechanism an eating disorder can be unpacked and helped but it requires a lot of work and probably more than our current system is designed to do.

Listening to me. Listening to my experience and understanding it in relation to my life and my experience. Don't frame me in relation to what your textbook says. It's wrong that is not my experience. The practitioners who get that.... they are awesome.

It's ok to not be perfect. to be human to struggle. but please listen to us and be open to the fact that our experiences might not be what you expect. That our identities (trans and ED) might intersect and might not. That we aren't what you read in a textbook. Understand that you are labeling us or not labeling us, taking us seriously or not. Ignoring us or spending too much time focusing on us, this all impacts us and not always how you think it will. There might be some good things but explore with us the negative and complicated things. Talk with us. Don't assume!!!!!

\section{Educate Yourself}

Reading about experiences of [trans folx with eating disorders], as well as researching both topics in general.

Less time spent explaining both/either condition(s) to provider(s) and [receive] overall more treatment.

Education - but I think it's more than that. I think we need a cultural shift. I think we need to figure out how to get healthcare providers to care. I think the question needs to be, what would make you want to learn about trans folx with [eating disorders]. Ask that to doctors. I think doctors need to be reflexive. To learn about social injustice and its impact. To question medicine as a discipline and see how that impacts patients based on their social locations. I think medicine is about right and wrong/cure vs illness.... people's identities aren't like that, they are multilayered and complex. If you could teach that, maybe doctors would approach patients differently. Maybe that's why 
I've had better experience accessing help from professionals who receive that type of training.

\section{Incorporate a Continued and Shared Education Model into your Workplace}

Workshops done by local organizations, perhaps in tandem with social workers who are familiar with the overlap of trans and gender non-conforming individuals and mental health disorders. Education is key.

We're tired of explaining who we are when we're looking for non-trans related healthcare. I don't need to explain to every [emergency room] nurse who has clear access to my file. (I understand they can't sift through the whole thing, but there should be a clear indicator at the top of my gender identity and pronouns).

Maybe have a meet and greet, maybe even in med school. How about some form of education that humanizes the patient? As opposed to just a diagnosis. Some economical way, not just financial, with time, energy, and trust. If there was some way to cut the gaps between the basic humanity that we all share to get to ok, this person is not weird because they are trans... they are a person. Whatever meeting people outside of a formal medical context looks like, would be a way of finding peoples humanity. The level of scepticism and miss-trust in the trans community... against the medical community is outstanding... I don't know what med school looks like in terms of trans people or nutrition... I think most healthcare practitioners are willfully ignorant of nutrition. I get it that general practitioners... need to have a big enough knowledge to catch someone, especially in the trans community and get them help. This doesn't necessarily mean residential eating disorder treatment... current eating disorder care is not the only solution. We know the brain is plastic, let's use neuroplasticity to work on eating disorders.

\section{Incorporate Learnings into Your Personal Practice}

Please suspend any assumptions about my gender identity and eating disorder when you work with me.

Please recognize that trans people have additional concerns and be prepared to adapt your ED model after listening to them.

Add dysphoria related questions to follow-up or intake questions so that I feel less erased! For example, when being asked "how much has weight/ shape influenced your self-esteem" as and evaluation question, for trans patients they could ask "how has the positioning of weight in your body influenced your connection to your gender" or something of the like. also, acknowledgement that tolerating one's body can be additionally difficult and multifaceted, and recognition that there can be self-harm functions of 'eating disorders' and be willing to raise and address that. 
More comprehension of what dysphoria is, the diverse ways it can affect people, the other functions of 'eating disorders' like shrinking yourself to hide, altering body, selfharm, etc., the impact of cis-normativity in 'eating disorder' spaces on trans patients and the comfortability levels.

Ask me my pronouns. Ask me anything, don't assume. Listen to me and actually hear me. Work with me. Take into account that everyone's experiences will be different. We are not boxes on a form. Sometimes we won't match your understanding.

Please recognize that trans people have additional concerns and be prepared to adapt your 'eating disorder' model after listening to them.

I feel like nothing less than an overhaul of the way we view transition related healthcare into something far more wholistic and proactive care for eating disorders is necessary. Like my family doctor has not asked about how I am doing with eating in over a year now. Do I disclose that it is a daily struggle to eat right now?

There is a fundamental mistrust of physicians. I don't trust them completely; I don't share everything. I'm not sure they could even help me. If I shared my eating disorder, and that I don't want residential, I'm not sure they have an option outside of ticking a box on their screen that might highlight they need to monitor my weight, that isn't helpful. As for the Healthcare system, sometimes it's not writing a prescription and sending me on my way. It's spending their time with me. Honestly, if I'm down the rabbit hole, you monitoring my weight doesn't help me... understand how traumatic it is to be asked to be weighed. I didn't realize at the time how traumatic it even was to get on a scale. Its problematic... Help us. Do your jobs and help us... help is going to look different for everybody. To someone out there, maybe a cooking class would be helpful for them, for someone else that might be detrimental. A solution to me, seems beyond the scope of our healthcare system. The model doesn't exist because it is wholistic. It's expensive. I've met a lot of cool trans people with a lot of cool skills. The amount of work they have put into surviving is astounding. Make resources available to thrive and succeed. It isn't just prescribing HRT [hormone replacement therapy].

I think I've said it.... listen. don't assume. you don't have to fix us. there is nothing wrong with us. and yes, we may be struggling. and listen to our needs. we know programs are limited. funding is limited. you need to change the DSM criteria because so many people who are struggling are left out. ED's and Trans identities impact each other but aren't caused by each other. Trans people struggle but that doesn't mean we are flawed any more than anyone else. We need culturally (lack of a better word) informed supports created by us. We need supports that include us.

\section{Incorporate Learnings into Your Workplace(s) and Discipline}

I had a family doctor who I came out to and asked for hormone replacement therapy. She didn't handle it well. not terribly but did end up calling me back in a few days 
asking if I would be willing to come back in for a conversation. She had done all this research and apologized for not handling that conversation well. She acknowledged that she hadn't had any training and could have/should have done better. She didn't think she was going to see me again and was grateful I had given her a second chance.

There needs to be a lot more follow up after gender reassignment surgery to check on a patient's mental health. The work pre and post op are huge and beyond what I thought I'd be dealing with. I would say I was unprepared for the level of work I had to do pre and post op... I was unprepared and dealing with an eating disorder while recovering from surgery [which] just made recovery from both that much harder... I think along with gender reassignment surgery there should be included some sort of therapy that accompanies pre and post op care. More than is currently available.

Just because someone isn't down the rabbit hole with an eating disorder, doesn't mean they are asymptomatic. That care needs to be there. This does not mean asking someone's fucking weight. this isn't how you monitor someone's health. It's asking, what is your favourite meal, or maybe there are ways to ask about food indirectly, that is a better way of asking and assessing where someone is at psychologically around food. To be able to determine when the person is talking, or the eating disorder is talking. Our relationship with food is complex.

Accessing traditional [eating disorder] support was hard for me because my experiences did not match those of a lot of the cis women there. It made me feel really different and silenced. It didn't always validate my experience and felt isolating at times.

\section{Move Beyond your Understanding of the World}

Believe trans people. Full stop. Understand that we have done a lot of complicated shit to survive and we're not mentally ill. We are literally existing in a liminal space that is a sociological construct.

Do not make assumptions about patients and do not assume that your experiences mirror another person's experiences.

I think that providers need more training to step outside the "overvaluation of weight and shape" ED model so that trans people feel more heard and comfortable and validated when sharing their experiences, and that there is hope that they can heal.

Just like cis individuals, our experiences vary widely, and we should all be treated on a case by case basis.

Usually people in the ER see my name and just start using male pronouns which I prefer to female pronouns, but I would like they them or for people to ask. 
My therapist who is trained as an occupational therapist and psychotherapist has said really hurtful things at times. But we have managed to work through them mostly. She struggles with non-binary. She has said this to me, and it is clear that she treats me differently based on whether she sees me as male or female.

Admitting ignorance, is a powerful tool in a healthcare practitioners' arsenal. To say I don't know, let's figure this out, instead of acting as the authority. Maybe saying, what can I do for you, what does getting healthy around food look like for you?

\section{Unpack your Biases and Practice Reflexivity}

I've learned that people who knew me pre transition treat me differently. I'm somehow more human to them.

It's ok if you don't know it all. Don't pretend to know it all. Help us navigate the system in a way that feels good to us. And please do your own work. Please learn how to be reflexive. Please learn about social justice. The fact that you show up is great, but we need more, be open to making mistakes and learning. Be open to the fact that the world is different for your patients.... that things are more complicated than even sick and well. Understand that [eating disorders] are complex and complicated and that gender isn't problematic. I need you to be open. Because when you aren't... I've experienced such great harm from you... I appreciate when you are honest with me. I appreciate when you respect me. I appreciate when you start to learn about where your biases are. Because we all have them.

I have had some terrible experiences where doctors and psychiatrist just make a ton of assumptions about me because of my gender. I have accessed all my medical records for my entire life and 4-5 years ago the way people talk about me completely changed. They were all doctors who didn't know me pre transition and suddenly everything I did was constructed as me having a flawed personality. I see it with my friends as well. No mention of a flawed personality until after transitioning. Basically, if people only know the shitty stats about trans people they tend to frame you under those and there is no winning. I feel like I have to be as close to perfect as possible.... It's a shitty place to be in. I feel like my [eating disorder] went from being a coping tool and maybe even just part of me to something that now works against me in a whole new way and just confirms how fucked up trans people are to doctors and nurses.

\section{Let Trans and Nonbinary Folx Make Their own Healthcare Decisions}

Even though I am healthy by medical standards, I actually have to "practice" eating on a near daily basis...tell that to my doctor, they just sort of shrug and are like well, we'll monitor your weight and if it gets problematic, we will do something about it. And like getting on a scale is literally the worst thing anyone can ask me to do. So, has my act of opting not to get weighed anymore been taken as a sign of refusal of care? 
Let me work though what works for me. Offer support where you can but let me decide when and where and how as much as possible.

Yes, I want to see all healthcare professionals understand that its ok if you can't fix something. I want to see them be able to sit in that uncomfortable space of not knowing or not jumping into treatment.... waiting for the patient to say ok where possible.

[Don't] pressure me to get on a scale. Period. Even blind weighing me.

I was hospitalized for a couple of weeks in high school, for disordered eating, but I was never told outright (I think because I'm Assigned Male at Birth).

\section{Transitioning can Help with 'Eating Disorder' Recovery}

Sport and eating, it's all a mechanism of control for me, it wasn't the body I wanted but it was the body I could get... [an] eating disorder can be used to transition.

Healthcare providers need to trust trans people to know their bodies better than anyone and to listen to trans people. So much of trans healthcare is rediscovering lost knowledge.

It's not [a] mental illness it's how we cope... helpful and/or unhelpful, they got us through. Most of us want them to go away but we don't have the means. I think eating disorder treatment is just as essential as surgeries and whatever the transition process is for someone. I developed [an eating disorder] to stop myself from going through puberty and it fucking worked and I don't need that anymore. 


\section{CHAPTER 6. IMPLICATIONS}

The major findings of this research illustrate the complexities that can come from holding multiple marginalized identities. It is clear from the findings that while participants hold multiple identities at the same time, healthcare is set up in such a way that it is rarely able to address more than one identity or experience at a time. What is also clear is that many healthcare providers and institutions are not aware of how systemic oppression such as transphobia and sanism are operating and by default, are therefore not aware of the impact this has on service users.

What stood out for me was the emphasis on access to transition related healthcare, such as gender affirming surgeries and hormone replacement therapy. It is clear that access to supportive gender affirming care leads to better overall health and assists with 'eating disorder' recovery. It is important that participants also highlighted the need for these services to be affordable as finances can be a barrier. Especially since trans people can be discriminated against in both finding and maintaining employment (Hanssmann, 2008, p. 7). In relation to this study, when participants were asked what percentage of their monthly income they could spend on nonessential items or the percentage of income that was left after paying for housing, food, transportation, etc., Three participants said they had no income left and two participants said they had $5 \%$ and $10 \%$ to spend. While I did not ask for current income, it highlights that participants do not have much to spend on healthcare out of pocket.

Another important finding is that participants rarely spoke about 'eating disorder' behaviours but highlighted that they don't always meet the diagnoseable criteria, nor do they feel that their healthcare providers would know what to look for. It is clear that participants do not feel that supports exist, nor do they feel supported by most health care professionals in the way they need. I think it is important to highlight the structural issues within these findings. 
Healthcare providers are educated within a system that does not prepare them to work with trans patients. How can we expect healthcare providers to provide excellent care for trans patients, particularly those with 'eating disorders if the system they are being trained within has a lengthy history of pathologizing trans people as 'mentally ill'. Particularly when GID is still located within the DSM.

For participants, not always meeting 'eating disorder' criteria and not being represented in assessment tools were barriers to accessing supports. Many participants spoke about how a medicalized focus on weight as a factor of health rather than a person's 'symptoms' or felt distress was also a barrier that caused some participants great distress. Participants spoke to how a focus on weight rather than symptoms only acted to sustain a focus on treatment rather than prevention. Dr. Jennifer L. Gaudiani (2019), a board-certified internal medicine physician who specializes in the treatment of 'eating disorders', has said that weight is not a good predictor of health. She instead uses a Health At Every Size (HAES) philosophy and will only "check the body weight on any patient unless [she] is monitoring [a] planned weight restoration in the context of nutritional rehabilitation (p. 136). This focus on weight suggests that weight loss is the only indicator of an 'eating disorder', while contributing to an understanding that only those who achieve a low body mass are entitled to access 'eating disorder' support.

Participants felt that training or education may be a solution to receiving 'better' healthcare. Based on participants' responses I would suggest that this education needs to include trans and 'eating disorder' health knowledge with a focus on how to practice in a way that is client centred and trauma informed. This is critical since trans individuals in this study have experienced healthcare itself as a source of trauma. When healthcare providers dismiss trans people's experiences of trauma because it's not happening now, it is clear that they do not 
understand that for trans people who continue to be traumatised by healthcare, trauma might actually be happening in that moment. If you experience transphobia in the world and by healthcare providers who are being transphobic, that trauma is happening in the moment. Healthcare providers need to be able to recognize and validate trans people's experiences if they hope to provide excellent healthcare. For this reason, I would suggest that training should also include how to recognize one's biases and work to overcome them.

One advising member of this research told me that they really wanted an apology from the healthcare system for the harm they have experienced. They went on to say that, they have concerns about how changes to healthcare may cause to problems for trans and nonbinary people. For them, better trans informed care opens the doors to more conversations that aren't necessarily happening right now. If those conversations were to happen, they may be misconstrued.

If I were to have some of these conversations with healthcare providers [before surgery] it may have sounded like I wasn't sure about transition even though I was. How do I have those conversations if I don't feel safe exploring these questions wouldn't make me feel safe. Would my feelings be misread because people don't understand where I'm coming from as a trans person?

I think this is important to highlight this as we work towards recommendations for healthcare and healthcare providers that we also consider what new forms of oppression may begin to operate from these changes.

What has proved fascinating to me is that while most 'eating disorder' literature speaks to the detriment of 'eating disorders', for research participants, what is traditionally pathologized was also a tool of survival. While I would not advocate for individuals to engage in 'eating disorder' behaviours as we know they can be detrimental to one's health, systemic oppression transphobia and sanism- could be argued to be equally, if not more detrimental. For participants, 
'eating disorders' were a way they could both cope with sanism and transphobia, while also assisting them to change their body shape to be more congruent with their gender. That is, until more informed healthcare providers provided access to medical transition. At which point, 'eating disorder' experiences were pathologized; further pathologizing trans identities, rather than transphobia.

This shows just how resourceful and skilful trans individuals with 'eating disorders' are. Not only were they able to find a way to navigate transphobia and sanism, in a way that may assist them in achieving a more congruent physical appearance to their gender, participants were able to find support within their communities even when healthcare failed them. This was also highlighted in many participants' discussions of the importance of friends and LGBTQ2S+ communities. For participants, these communities act both as a support and a way of determining which services might be safe to access and trans informed.

I do question some of the framing of these experiences. How does our western framing of 'eating disorders' and GID, influence our own understandings of our experiences? Watters (2010) discusses how in Hong Kong, 'Anorexia' was understood to be a somatic disorder with service users complaining of bloating rather than a desire to be 'thin' (p. 42). It was not until after 1994, when Chinese newspapers began publishing stories that incorporated an American understanding of 'anorexia', that service users in Hong Kong and China, began to describe their experiences of 'anorexia' using an American understanding (Watters, 2010, p. 42).

Given that one participant stated that their 'eating disorder' and gender identity were unrelated to each other and another participant stated that it was not until they were receiving 'eating disorder' treatment that they realized there was a link. When I think of these responses in the context of Watters (2010) article, it makes me wonder how much we all understand our 
experience through dominant narratives. This is not to take away from people's understanding of their experiences but has led me to question this continual embracing and rejecting of dominant narratives.

If we understand our experiences through dominant narratives and describe them within these dominant narratives, it maintains the status-quo of systems designed to serve service users who experiences fall within dominant narratives. In this case, the narratives are not dominant narratives but a subsect of narratives, since dominant narratives are set up for white cisgender women as service users. If this is the case, while the findings of this research are very much needed in relation to the current 'eating disorder' healthcare system, were participants able to respond to the survey in a way that allowed for possibilities beyond our understanding of the current healthcare system? Would individuals experience gender dysphoria and body dysmorphia if there was room for more than a binary experience of gender in the world and if fat phobia did not prevail in Canada and the United States?

\section{The State of the World in Relation to the Findings}

I think it is important to remember that we are all connected to the world events and these systems as a whole. As I began my research, Canada was ignoring the United Nations Declaration on the Rights of Indigenous Peoples (UNDRIP), in order to complete construction on the coastal GasLink pipeline on Wet'suwet'en land. I obtained ethics approval two weeks into the rest-in-place orders in Ontario due to Covid-19. The findings of the research were compiled as the president of the United States put forward an executive order to remove the rights of LGBTQ2S+ individuals. This was in the midst of Black Lives Matter protests after the murder of George Floyd -while reports of the murders of Black trans people have been surfacing regularly with little mainstream media coverage. I began writing the findings section as J.K. Rowling, the 
author of Harry Potter, decided to release a transphobic letter stating her concerns for trans youth and the feminist movement due to the strength of trans advocacy movements. And as I come to the completion of this MRP, we are now all living with the reality that Covid-19 has drained the majority of the limited resources our healthcare system had to begin with. While being no closer to knowing what the costs will be physically, emotionally, and spiritually moving forward.

You may be wondering why I have chosen to include a synopsis of the current situation in the world. I have chosen to do so as a way of decentering white settler colonialism and of highlighting the very real reality individuals experiencing marginalization face today. Sonya Rene Taylor (2020), states that we are not working for social justice if we are not including everyone in our calls for social justice. The reality is this research is very white. And while a decentring of settler colonialism was at the forefront of this research, we must recognize that calls for liberation must not erase the experiences of non-white trans people with 'eating disorders'. In a moment where the world is changing and voices might be heard, how do we do differently? How do we as social workers and healthcare providers hold ourselves accountable to working towards social justice for all? Or, how do we allow ourselves to see who is missing from social justice movements?

We must also acknowledge that it is not enough to simply make 'eating disorder' treatment more inclusive. "Decolonization never takes place unnoticed (Fanon, 1963, p. 36, as cited in Tuck \& Yang, 2012, p. 7). Settler colonialism and its decolonization implicates and unsettles everyone" (Tuck \& Yang, 2012, p. 7). While the findings of this study are important, we must not forget that this study is still constructed within colonial structures and many voices are missing from this study. It would not be fair to believe that any study would accurately be able to represent all voices, but this study is very limited. While individuals may share 
intersectional identities, it does not mean that they will need or want the same things. It is also not fair to assume that individuals with shared marginality would believe in the same approaches to their concerns. "Decolonization must involve changing systems to make space for all knowing. It makes room for understanding wellness as the connection between all things, not just the relationship connections between human beings" (Lane et al., 1985, p. 26, as cited in Peterson \& Chatterjee, 2017, p. 140).

\section{Implications for Social Workers and Healthcare Providers}

I recently attended a doctor's appointment at a trans health clinic where I was asked a variety of questions in regard to transition related healthcare. When I asked how these questions related to my concerns, they said, "well we are a clinic that specializes in trans health." This would not have been strange except for the fact that I was not there for support around transition. I was there as a person accessing healthcare who also happens to be trans. I was referred there because the doctor specialized in both my health concern and trans medicine. The problem was, while they had an awareness of the needs of trans patients they seemed to be operating from the results of a trans healthcare study, rather than a client centred approach.

One participant mentioned that even when they accessed a trans specific 'eating disorder' resource, it was still not what they needed as they still did not see themselves reflected in the other participants. I think it is important for us as social workers and healthcare providers to sit with this. It is not enough to make a checklist of 'good healthcare practices for trans folx' and implement it. Healthcare providers need to learn what trans folx with 'eating disorders' may need and want. Educate themselves and implement their learnings into all aspects of their practice, while being reflexive and operating from a place of client centred care. Use your knowledge to make accessing your space and staying in your space as safe as possible for trans 
patients - before they even get to your office. Never assume all trans service users will have the same needs. Even with knowledge of trans 'eating disorder' healthcare, you need to ask clients why they are in your office and what they want. Then you incorporate 'trans specific' knowledge as you work towards a solution, all while respecting your client's decisions.

In this same healthcare appointment, the doctor asked me about my MRP topic. I responded with, 'the healthcare experiences of trans people', she cut me off before I could say, with 'eating disorders'. I could be wrong with my interpretation, but as I told her my topic, she had a look of fear on her face. I've come to learn that healthcare providers have one of two reactions. The first being, a sigh and an acknowledgement of how bad healthcare has traditionally been for trans folx. The second reaction is fear, it almost appears as if they are concerned what I might write about them, and probably rightly so. But what that reaction tells me is that at some level they have an understanding of how bad trans healthcare is for trans folx, they just don't want to implicate themselves as a contributing and sustaining factor.

So, I challenge social workers and other healthcare providers - Aim to do better. Begin from a harm reduction model. Ask yourself how you would want to be treated when you access healthcare and start there. For myself, I want to start from a place of kindness and compassion. A place that does not assume that I could ever understand someone's experience no matter how much I may identify with them or share similar identities with them. It means being reflexive and open to feedback. Instead of assuming something is a problem, ask in the words of Gabor Mate, "How has this served you?" (Ferriss, 2018). Because what the results of this survey has shown me, is that healthcare is not meeting the needs of trans folx with 'eating disorders'. And while this research has given us a glimpse into what some of the needs of trans folx with 'eating disorders' are, there is no way that it will encompass everything. Needs will change and as my 
experience at the doctor illustrated, even trans specific health clinics will not always get it right. Perhaps if we approached healthcare professions as being the ally we would want for ourselves, we might provide something closer to the healthcare trans and nonbinary folx with 'eating disorders' want. 


\section{CHAPTER 7. CONCLUSION}

It is clear that trans individuals with 'eating disorders' do not feel as though their healthcare needs are being met. Participants highlighted barriers to care such as difficulty finding or accessing trans and 'eating disorder' informed healthcare and healthcare practitioners. For participants very few healthcare providers understand the relationship between trans identities and 'eating disorders'. Of the available services participants accessed, many were not designed for trans or nonbinary individuals or for trans and nonbinary individuals with 'eating disorders'. Participants highlighted that there is both a need for healthcare providers to understand that there is a link for some individuals between gender identity and 'eating disorders'. With participants highlighting a need for healthcare providers to work towards encompassing an intersectional approach within their agencies as well as their own practice.

Participants believed that it was a lack of awareness around 'eating disorders' and gender identities, as well as the intersection between these identities that contributes to a lack of awareness by healthcare providers. This research has found that this is imperative that healthcare providers and training institutions move towards a broader understanding of possible human experiences and a continued dedication to exploring new possibilities. Since many social workers and healthcare providers will engage with service users from a variety of social locations.

An important and concerning finding is that accessing healthcare can be traumatic for trans individuals with 'eating disorders'. It is important that we as healthcare providers recognize this, as without this understanding we are continually contributing to the harm of service users. Although this may be done unintentionally, it is important to recognize that that does not take 
away from the harm we may be causing. This can make it even more challenging for trans and nonbinary individuals to access healthcare in the future.

This research also found that despite navigating transphobia and sanism within their lives and healthcare, trans individuals are extremely skilled at supporting themselves and finding healthcare and healing support in unexpected places. For participants friends and community played an important role in both supporting trans individuals with 'eating disorders' and assisting them to find gender affirming, knowledgeable safe healthcare professionals and organizations.

Based on the findings of this research, we were able to compile a list of suggestions for social workers and healthcare providers as a way of working towards making healthcare more inclusive and safer for trans folx with 'eating disorders'. Suggestions included, listening to service users, educating oneself on both gender and 'eating disorders', committing to continued education, incorporating new learnings into your own practice as well as your workplace and discipline, a commitment to begin moving beyond one's own understanding of the world, a commitment to unpacking your own biases and practicing reflexivity, allowing trans and nonbinary people to make their own healthcare decisions, and understanding that access to medical transition without gatekeeping can help with 'eating disorder' recovery.

While these findings are not by any means an exhaustive list of ways to improve healthcare for trans and nonbinary people with 'eating disorders', my hope is that this research will highlight the need for continued conversations, further research, and advocacy. That it will lead to change within healthcare in a way that begins to make healthcare safer and more inclusive to trans people. And that it will highlight the need to decenter white colonial knowledge and power in a way that allows for more possibilities of what healthcare could look like for all of us. 


\section{APPENDIX A \\ Checklist for Participatory Action Research with Transgender Communities Singh, Richmond, \& Burnes (2013, p. 97)}

$\square$ Assess one's intersecting identities (e.g., race/ethnicity, gender identity and expression, etc.) as they relate to privilege and oppression and power as a researcher

Clearly articulate a theory on gender and determine how this theory informs methodological choices

Reflect on researcher positionality related to transgender concerns

$\square$ Conduct a current transgender literature review informed by both peer-reviewed sources and other nonacademic sources of information (blogs, advocacy websites, novels etc)

Provide and/or attend presentations or activities at community centers that serve transgender individuals, so that a potential PAR relationship could be initiated

$\square$ Determine community needs by working collaboratively with transgender people and communities

$\square$ Identify the opportunity for advocacy associated with the PAR study

Work with a research team order to establish expectations and accountability related to researcher privileges, assumptions, and biases

$\square$ Use sampling practices that ensure a diverse and representative population

Share all aspects of the research process and data with informants and communities (stake holders) - and be sure to ask for feedback and input along the way

$\square$ Practice humility about one's knowledge and assumptions, apologize as necessary, and make changes to the study based on this learning

$\square$ Understand historical oppression of transgender people and communities

Identify how your personal liberation is connected to the liberation of the informants and participants with whom you work 


\section{APPENDIX B}

Katz-Wise and colleagues' (2019) on community-based participatory research principles (Katz-

Wise et at., 2019, p. 190)

Table I. Application of community-based participatory research principles in the TTFN Project.

\begin{tabular}{ll}
\hline CBPR principles & Application of principles in the TTFN Project
\end{tabular}

I) Recognize community as a unit of identity.

2) Build on strengths and resources within the community.

3) Facilitate collaborative partnerships in all phases of the research.

4) Integrate knowledge and action for the mutual benefit of all partners.

5) Promote a co-learning and empowering process that attends to social inequalities.

6) Involve a cyclical and iterative process.

7) Address health from both positive and ecological perspectives.

8) Disseminate findings and knowledge gained to all partners.
Community was defined as TGN youth and families, and the organizations and individuals who serve these families.

Researchers partnered with community members to use the community's existing networks for study recruitment; community members reviewed study materials based on their own experience and expertise.

Community members provided feedback on study design, recruitment, study materials for data collection, and interpretation of results, and additionally served as members of the research team.

Results from this study will inform future research and clinical practice with TGN youth and families, as well as inform the development of an intervention to improve family functioning and decrease stigma in families with TGN youth, which will benefit the community.

Community members are empowered to share their experience and expertise to improve the project and ensure that the study outcomes will be useful for the community.

Study design and materials have evolved over time based on community feedback.

TTFN takes a holistic approach in assessing both risk and resilience of TGN youth and families, as well as considering how contextual factors, such as extended family, school, and the political climate affect family members' experiences.

Non-academic summaries of research findings were prepared to disseminate to the community for the purpose of obtaining feedback on interpretation, as well as increasing knowledge within the community.

Note: Principles adapted from Israel et al. (1998).

TTFN: Trans Teen and Family Narratives; TGN: transgender and gender nonconforming; CBPR: communitybased participatory research. 


\section{APPENDIX C}

\section{Survey Questions}

1) Are you over the age of 18 , identify under the trans umbrella, identify as someone who is currently or has experienced an 'eating disorder', and you have accessed healthcare where you have discussed your trans identity and 'eating disorder' with a healthcare provider as outlined above?

\section{Demographic Information}

2) Please describe your gender identity

3) Please describe your sexual orientation

4) Please describe your race and/or ethnicity

5) Approximately, what percentage of your monthly income can you spend on non-essential items? (The percentage of your income that is left after paying for housing, food, transportation, etc.)

6) How old are you?

7) How would you describe your 'eating disorder'?

8) Are there any additional demographics about yourself that you would like to provide?

\section{Data Collection Questions}

9) How would you describe the relationship between your gender identity and your 'eating disorder'?

10) Have you accessed 'eating disorder' healthcare and/or supports? (For the purpose of this survey Healthcare provider is defined as a person who provides healthcare service to you. This may include Doctors, Nurses, Social Workers, Therapists, Dieticians, Nutritionists, Occupational Therapists, Physiotherapists, Traditional Chinese Doctors, Naturopaths, Chiropractors, Massage Therapists, among others)

11) If you have accessed 'eating disorder' healthcare and/or supports, would you mind describing what kind of 'eating disorder' supports have you accessed?

12) If you have not accessed 'eating disorder' healthcare and/or supports, would you mind describing whether this was by choice or due to lack of services. Please explain

13) Have you accessed gender identity healthcare and/or supports? 
14) If you have accessed or are unsure if you have accessed gender identity healthcare and/or supports, would you mind describing what kind of gender identity supports you have accessed?

15) If you have not accessed gender identity healthcare and/or supports, would you mind describing whether this was by choice or due to lack of services. Please explain

16) What have your healthcare experiences been like as a trans person with an eating disorder? Please speak to positives, negatives, and neutral experiences.

17) Is there anything that your healthcare providers do or have done that was particularly helpful for you as a trans person with an 'eating disorder'? Please explain

18) Thinking about your answer to the previous question, if your healthcare provider does/did something that is/was helpful, is it something that you would like to see other healthcare providers do when working with trans and nonbinary individuals with experiences of 'eating disorders'? Please explain

19) Is there anything that a healthcare provider or healthcare organization could have done to improve your healthcare experiences as a trans or nonbinary person with experiences of an 'eating disorder'? (Please think of things that could have been done differently or things that would have made your experience better?)

\section{These next questions focus specifically on accessing healthcare primarily related to your 'eating disorder'}

20) If you have accessed healthcare which focused primarily on your 'eating disorder', did accessing health care for your 'eating disorder' have an impact on your gender identity? Please explain

21) If you were not 'out' about you gender identity when you first accessed 'eating disorder' healthcare and/or supports, did 'coming out' or disclosing your gender identity have an effect on your gender identity or 'eating disorder'? Please explain

22) If you have accessed healthcare which focused primarily on your gender identity, did accessing healthcare for your gender identity impact your 'eating disorder'? Please explain

23) If you were not out about your 'eating disorder' when you first accessed gender identity supports, did 'coming out' or disclosing your 'eating disorder have an effect on your gender identity or 'eating disorder'? Please explain

24) Have you ever accessed healthcare supports that were designed specifically for trans or nonbinary people with experiences of 'eating disorders'?

25) If yes, what were your experiences like? Please explain. If no, is this something you would access if given the choice? 
26) What do you think is important for health care providers to know when working with trans individuals who have experiences of 'eating disorders'? Please explain

27) Why do you think it is important for health care providers to become more informed about trans and nonbinary people with experiences of 'eating disorders'? Please explain

28) What do you think would help health care providers to become more informed about trans and nonbinary people with experiences of 'eating disorders'? Please explain

29) As a trans or nonbinary person with experiences of an 'eating disorder', is there anything you would like to say to health care providers? Please explain

The next questions focus on what you would like to see happen with the results of this research study and how they might benefit trans and nonbinary people with 'eating disorders'

30) In what ways would you like to see the research results shared? (ex. a poser or infographic, website, pamphlet, newspaper or magazine article, through visual art or other creative medium, etc). Please explain

31) Are you comfortable with the research results being shared in alternative formats? (ex. a poser or infographic, website, pamphlet, newspaper or magazine article, through visual art or other creative medium, etc). Please explain

32) Which alternative format would you prefer to see the research results shared and why? (ex. a poser or infographic, website, pamphlet, newspaper or magazine article, through visual art or other creative medium, etc). Please explain

33) Do you have concerns with the research results being shared beyond my final research paper? Please explain

34) If you have concerns about sharing the research results of this study beyond my research paper, are there things I can do as the researcher to reduce or lessen your concerns when sharing the final research results? Please explain

35) Do you consent to the sharing of the research results of this study in a format beyond my final research paper?

36) What is the most important message you would like to convey to health care providers? Please explain

37) Is there anything else you would like the research team to know?

By clicking SUBMIT I am consenting to participate in this study * I understand (check box) 


\section{Survey Submission Response:}

Beyond Binaries: What trans adults with 'eating disorders' need from healthcare (survey). Thank you for participating in my research. Remember to close this window and delete your browser history if you want to fully protect your anonymity as a participant. If you have any questions, comments, or concerns, feel free to reach out to the me any time by emailing zachary.grant@ ryerson.ca

I have provided the support resources once more in case any of the research questions have brought up unpleasant, upsetting, or triggering memories you are encouraged to seek support from your loved ones or call one of these helplines to anonymously debrief or seek assistance or access support from one of these community organizations.

The Trans Lifeline

helpline by and for trans people

1-877-330-6366 (Canada)

1-877-565-8860 (US)

Toronto's Distress Crisis Centre

24-hour emotional support

416-408-4357 or text 45645

National Eating Disorder Information Centre (NEDIC)

1-866-NEDIC-20 (toll-free)

Toronto: 416-340-4156

Email: nedic@uhn.ca

Website: nedic.ca (Chat option available on their website)

The Gerstein Crisis Centre

24 hour emotional support

(416) 929-5200
Sheena's Place

Toronto Eating Disorder Support

416-927-8900

Email: info@sheenasplace.org

Website: sheenasplace.org

Body Brave

Hamilton Eating Disorder Support

PHONE: (905) 312-9628

Website: bodybrave.ca

The 519 Community Centre

LGBTQ2S services, groups and counselling in Toronto

Website: the519.org

Sherbourne Health Centre

Primary healthcare and groups for

LGBTQ2S individuals in Toronto

Phone: 416-324-4100

Email: info@sherbourne.on.ca

Website: sherbourne.on.ca 


\section{REFERENCES}

American Psychiatric Association. DSM-5 Task Force. (2013). Diagnostic and statistical manual of mental disorders: DSM-5 (Fifth ed.) American Psychiatric Association.

Anzani, A., Prunas, A., \& Sacchi, S. (2019). Facing transgender and cisgender patients: The influence of the Client's experienced gender and gender identity on clinical evaluation. Sexuality Research and Social Policy, doi:10.1007/s13178-019-00382-4

Ault, A., \& Brzuzy, S. (2009). Commentary: Removing gender identity disorder from the diagnostic and statistical manual of mental disorders: A call for action. Social Work, 54(2), 187-189.

Baksh (2016). Clarity and confusion: Epistemological struggles with Islamic identity and secular education. Qualitative Social Work, 15(5-6), 640-649.

Balasubramanian, J. (2014, February 17). \#EatingDisordersAreForWhiteWomen. BGD. Retrieved on 15 June 2020, from http://www.bgdblog.org/2014/02/eatingdisordersare forwhitewomen/)

Bauer, G. R., Zong, X., Scheim, A. I., Hammond, R., \& Thind, A. (2015). Factors impacting transgender patients' discomfort with their family physicians: A respondent-driven sampling survey. PloS One, 10(12), e0145046. doi:10.1371/journal.pone.0145046

Burstow, B. (2015). Psychiatry and the Business of Madness: An ethical and epistemological accounting. Palgrave Macmillan.

Burstow, B. (2016). Introduction to the Project: IE Researchers Take on Psychiatry. In Psychiatry Interrogated (pp. 1-20). Springer International Publishing.

Canadian Association of Social Work (CASW). (2005). Code of Ethics. Retrieved May 30, 2020 from https://www.casw-acts.ca/sites/default/files/attachements/casw_code_of_ethics.pdf 
Clark, N., Walton, P., Drolet, J., Tribute, T., Jules, G., Main, T., \& Arnouse, M. (2017). Melq'ilwiye (Coming together): Re-imagining Mental Health for Urban Indigenous Youth through Intersections of Identity, Sovereignty, and Resistance. In M. Morrow and L.H. Malcoe (Eds.), Critical inquiries for social justice in mental health (pp. 165-193).

Clark, N., Walton, P., Drolet, J., Tribute, T., Jules, G., Main, T., \& Arnouse, M. (2013). Melq'ilwiye: Coming together; Intersections of identity, culture, and health for urban Aboriginal youth. Canadian Journal of Nursing Research, 45(2), 36-57. Medline:23923736

Claudino, A.M., Pike, K.M., Hay, P. et al. The classification of feeding and eating disorders in the ICD-11: results of a field study comparing proposed ICD-11 guidelines with existing ICD-10 guidelines. BMC Med 17, 93 (2019). https://doi.org/10.1186/s12916-019-1327-4

Coelho, J. S., Suen, J., Clark, B. A., Marshall, S. K., Geller, J., \& Lam, P. (2019). Eating disorder diagnoses and symptom presentation in transgender youth: A scoping review. Current Psychiatry Reports, 21(11), 1-10. doi:10.1007/s11920-019-1097-x

Cohn, L., Murray, S., Walen, A., \& Wooldridge, T. (2016). Including the excluded: Males and gender minorities in eating disorder prevention. Eating Disorders, 24(1), 114-120. doi:10.1080/10640266.2015.1118958

Coutin, A., Wright, S., Li, C., \& Fung, R. (2018). Missed opportunities: are residents prepared to care for transgender patients? A study of family medicine, psychiatry, endocrinology, and urology residents. Canadian medical education journal, 9(3), e41-e55.

Daley, A. (2013). Spaces in Place: Negotiating queer In/visibility within psychiatric and mental health service settings. In B.A. LeFrancois, R. Menzies, \& G. Reaume (Eds.), Mad 
Matters: A critical reader in Canadian Mad studies (pp. 298-308). Canadian Scholars' Press Inc.

Diamond, S. (2014). Feminist Resistance against the Medicalization of Humanity: integrating knowledge about psychiatric oppression and marginalized people. In B. Burstow, B.A. LeFrancois, \& S. Diamond (Eds.), Psychiatry Disrupted: theorizing resistance and crafting the (r)evolution. (pp.194-207). McGill-Queen's University Press.

Didyk, L. A. (2014). Centering sanism: Stories \& visions for mad-positive mental health. Unpublished Major Research Paper. Toronto: Ryerson University, School of Social Work.

Diemer, E. W., Grant, J. D., Ph.D, Munn-Chernoff, M. A., Ph.D, Patterson, David A., M.S.W., Ph.D, \& Duncan, Alexis E., M.P.H., Ph.D. (2015). Gender identity, sexual orientation, and eating-related pathology in a national sample of college students. Journal of Adolescent Health, 57(2), 144-149. doi:10.1016/j.jadohealth.2015.03.003

Donaldson, A., Hall, A., Neukirch, J., Kasper, V., Simones, S., Gagnon, S., . . Forcier, M. (2018). Multidisciplinary care considerations for gender nonconforming adolescents with eating disorders: A case series. International Journal of Eating Disorders, 51, 475-479. doi:10.1002/eat.22868

Duffy, M., Henkel, K., Earnshaw, V. (2016) Transgender Clients' Experiences of Eating Disorder Treatment. Journal of LGBT Issues in Counselling,10 (3), pp.136-149.

Ewan, L. A., Middleman, A. B., \& Feldmann, J. (2014). Treatment of anorexia nervosa in the context of transsexuality: A case report. International Journal of Eating Disorders, 47(1), 112-115. doi:10.1002/eat.22209 
Ferriss, T. (2018, February 20). Dr. Gabor Maté: New paradigms, ayahuasca, and redefining addiction. The Tim Ferriss Show. Podcast retrieved from http://https://tim.blog/2018/02/20/gabor-mate/

Furman, E., Singh, A. K., Wilson, C., D’Alessandro, F., \& Miller, Z. (2019). “A Space Where People Get It”: A Methodological Reflection of Arts-Informed Community-Based Participatory Research With Nonbinary Youth. International Journal of Qualitative Methods. https://doi.org/10.1177/1609406919858530

Garner, T. (2017). (De) Pathologization: Transexuality, Gynecomastia, and the Negotiation of Mental Health Diagnoses in Online Communities. In M. Morrow and L.H. Malcoe (Eds.), Critical inquiries for social justice in mental health (pp. 312-332). University of Toronto Press.

Graca, Goncalves \& Martins (2018). Action research with street-based sex workers and an outreach team: A co-authored case study. Action Research, 16 (3), 251-279.

Gaudiani, J. L. (2019). Sick enough: A guide to the medical complications of eating disorders. Routledge.

Goldberg, A. E., Kuvalanka, K. A., Budge, S. L., Benz, M. B., \& Smith, J. Z. (2019). Health care experiences of transgender binary and nonbinary university students. The Counseling Psychologist, 47(1), 59-97. doi:10.1177/0011000019827568

Gorman, R. (2013). Mad Nation? Thinking through race, class, and Mad identity politics. In B.A. LeFrancois, R. Menzies, \& G. Reaume (Eds.), Mad Matters: A critical reader in Canadian Mad studies (pp. 269-280). Canadian Scholars' Press Inc.

Guss, C. E., MD, Williams, D. N., PhD, Reisner, S. L., ScD, Austin, S. B., ScD, \& Katz-Wise, S. L., PhD. (2016). Disordered weight management behaviors and non-prescription steroid 
use in massachusetts transgender youth. Journal of Adolescent Health, 58(2), S102-S103. doi:10.1016/j.jadohealth.2015.10.217

Hall, S. (Ed.). (2000). Representation: Cultural representations and signifying practices. Sage.

Hanssmann, C., Morrison, D., \& Russian, E. (2008). Talking, gawking, or getting it done: Provider trainings to increase cultural and clinical competence for transgender and gender-nonconforming patients and clients. Sexuality Research and Social Policy, 5(1),523. doi:10.1525/srsp.2008.5.1.5

Healy, K. (2001). Participatory action research and social work: a critical appraisal. International Social Work. 44(1), 93-105. doi: 10.1177/002087280104400108

Hiraide, M., Harashima, S., Yoneda, R., Otani, M., Kayano, M., \& Yoshiuchi, K. (2017). Longitudinal course of eating disorders after transsexual treatment: a report of two cases. Biopsychosoc Med, 11(32), 1-5. doi:10.1186/s13030-017-0118-4

hooks, b. (2014). Feminist theory: From margin to center (Third ed.). Routledge. doi:10.4324/9781315743172

Ibrahim, M. (2017). Mental health in Africa: human rights approaches to decolonization. In M. Morrow and L.H. Malcoe (Eds.), Critical inquiries for social justice in mental health (pp. 113-137). University of Toronto Press.

Israel, T., Walther, W. A., Gortcheva, R., \& Perry, J. S. (2011). Policies and practices for LGBT clients: Perspectives of mental health services administrators. Journal of Gay \& Lesbian Mental Health, 15(2), 152-168. doi:10.1080/19359705.2010.539090

Katz-Wise, S. L., Pullen Sansfaçon, A., Bogart, L. M., Rosal, M. C., Ehrensaft, D., Goldman, R. E., \& Bryn Austin, S. (2019). Lessons from a community-based participatory research 
study with transgender and gender nonconforming youth and their families. Action Research, 17(2), 186-207. doi:10.1177/1476750318818875

Kemmis, S., McTaggart, R., \& Nixon, R. (2014). The Action Research Planner: doing critical participatory action research. Springer.

Kia, H., MacKinnon, K. R., \& Legge, M. M. (2016). In pursuit of change: Conceptualizing the social work response to LGBTQ microaggressions in health settings. Social Work in Health Care, 55(10), 806-825. doi:10.1080/00981389.2016.1231744

Kirby, A. (2014). Trans Jeopardy/Trans Resistances: Shaindl Diamond Interviews Ambrose Kirby. In B. Burstow, B.A. LeFrancois, \& S. Diamond (Eds.), Psychiatry Disrupted: theorizing resistance and crafting the (r)evolution. (pp.163-176).McGill-Queen's University Press.

LaMarre, A., Rice, C., \& Rinaldi, J. (2020). Tracing Fatness Through the Eating Disorder Assemblage. In M. Friedman, C. Rice, \& J. Rinaldi (Eds.), Thickening fat: fat bodies, intersectionality, and social justice (pp. 64-76). Routledge.

LGBT Health Program (2015). Guidelines and Protocols for Hormone Therapy and Primary Care for Trans Clients. Sherbourne Health Centre.

Liegghio, M. (2013). A Denial of Being: Psychiatrization as epistemic violence. In B.A. LeFrancois, R. Menzies, \& G. Reaume (Eds.), Mad Matters: A critical reader in Canadian Mad studies (pp. 122-129). Canadian Scholars' Press Inc.

Lorde, A. 1984. Sister outsider. Berkeley, CA: Crossing Press

Lucas, G. (2020). Nalgona Positivity Pride. Retrieved on 15 June 2020, from https://www.nalgonapositivitypride.com/) 
Maegusuku-Hewett, T., Raithby, M., \& Willis, P. (2015). Life in the Pink Dragon's Den: mental health services and social inclusion for LGBT people in Wales. In J. Fish and K. Karban, (Eds.) Lesbian, Gay, Bisexual and Trans Health Inequalities: International Perspectives in Social Work (pp.79-95). Policy Press. [Peer Reviewed]

Maiter, S., Simich, L., Jacobson, N., \& Wise, J. (2008) Reciprocity: An ethic for communitybased participatory action research. Action Research, 6(3), 305-325.

Massaquoi, N. (2015). Queer Theory and Intersectionality. International Encyclopedia of the Social \& Behavioral Sciences. 19, 765-770, 10.1016/B978-0-08-097086-8.28073-2

Meyer I. H. (2003). Prejudice, social stress, and mental health in lesbian, gay, and bisexual populations: conceptual issues and research evidence. Psychological bulletin, 129(5), 674-697. https://doi.org/10.1037/0033-2909.129.5.674

Meyer, H. M., Morcarski, R., Holt, N. R., Hope, D. A., King, R. E., \& Woodruff, N. (2019). Unmet expectations in health care settings: Experiences of transgender and gender diverse adults in the central great plains. Qualitative Health Research, 1049732319860265.

Mills, C. (2014). Decolonizing global mental health: the psychiatrization of the majority world. Routledge.

Mills, C. (2017). Global Psychiatrization and Psychic Colonization: the coloniality of global mental health. In M. Morrow and L.H. Malcoe (Eds.), Critical inquiries for social justice in mental health (pp. 87-109). University of Toronto Press.

Morrow, M. (2017). "Women and Madness" Revisited: The promise of intersectional and Mad studies frameworks. In M. Morrow and L.H. Malcoe (Eds.), Critical inquiries for social justice in mental health (pp. 33-59). University of Toronto Press. 
Mulé, N.J. (2015). Much to be Desired: LGBT Health Inequalities and Inequities in Canada. In J. Fish and K. Karban, (Eds.) Lesbian, Gay, Bisexual and Trans Health Inequalities: International Perspectives in Social Work (pp. 27 - 43). Policy Press. [Peer Reviewed]

NEDIC. (2019). About NEDIC. Retrieved May 21, 2020, from https://nedic.ca/about/

NIED. (2020). About NIED. Retrieved March 19, 2020, from https://nied.ca/about-nied/

Nouvet, E., Sinding, C., Graham, C., Vengris, J., Fudge Schormans, A., Fullwood, A., \& Skeene, M. (2019). What are you (un)doing with that story? Qualitative Social Work, 18(3), 514529. doi:10.1177/1473325017735884

Oba, F. (2018). It Takes a Village-Schooling Out of Place: School Experiences of Black African Youth in Waterloo. (Publication No. 5726040) [Doctoral dissertation, Wilfrid Laurier University]. https://scholars.wlu.ca/etd/2015

Peterson, R. \& Chatterjee, S. (2017). Dancing with complexity: decolonization and social justice dialogues. In M. Morrow and L.H. Malcoe (Eds.), Critical inquiries for social justice in mental health (pp. 138-164). University of Toronto Press.

Petruik, C. R., Freeman, V. E., McGillicuddy, P., \& Dimitropoulos, G. (2017). Perceptions of health care social workers in ontario: Challenges and facilitators to reflective practice. Reflective Practice, 18(3), 339-357. doi:10.1080/14623943.2017.1279135

Poole, J. (2015). Doing Critical: introducing anti-sanist practice. Critical Approaches to Mental Health and Madness. Ryerson University: Toronto

Poole, J. (2014, June 4). Sanism [Video]. TED X. https://www.youtube.com/watch?v=hZvEUbtTBes 
Pinelli, A. (2019). Trans(cending) recovery: discussions with trans and non-binary folks around recovery in the context of eating disorders (Unpublished Master's thesis). McMaster University, Hamilton. http://hdl.handle.net/11375/25062

Pyne, J., Bauer, G., Hammond, R., \& Travers, R. (2017). In H. Parada \& S., Wehbi (Eds.), Reimagining anti-oppression social work research. (pp. 3-15). Canadian Scholars.

Robertson, N. (2018). The power and subjection of liminality and borderlands of non-binary folx. Gender Forum: An Internet Journal of Gender Studies, 69(69), 45-76.

Roche, B. (2011). New Directions in Community-Based Research. Wellsley Institute. Retrieved from https://www.wellesleyinstitute.com/wp-content/uploads/2011/11/newdirections incbr.pdf

Romanelli, M., Lu, W., \& Lindsey, M. A. (2018). Examining mechanisms and moderators of the relationship between discriminatory health care encounters and attempted suicide among U.S. transgender help-seekers. Administration and Policy in Mental Health and Mental Health Services Research, 45(6), 831-849. doi:10.1007/s10488-018-0868-8

Ross, L. E., Margaret, F. G., Daley, A., Steele, L. S., \& Williams, C. C. (2018). In spite of the system: A qualitatively-driven mixed methods analysis of the mental health services experiences of LGBTQ people living in poverty in Ontario, Canada. PLoS One, 13(8) doi:http://dx.doi.org.ezproxy.lib.ryerson.ca/10.1371/journal.pone.0201437

Sarkar, S. (2020). "May my children always have milk and rice" Problematizing the role of mothers in childhood fatness in India. In M. Friedman, C. Rice, \& J. Rinaldi (Eds.), Thickening fat: fat bodies, intersectionality, and social justice (pp. 51-63). Routledge.

Savvides, N., Al-Youssef, J., Colin, M., \& Garrido, C. (2014). Journeys into Inner/Outer space: Reflections on the methodological challenges of negotiating Insider/Outsider status in 
international educational research. Research in Comparative and International Education, 9(4), 412-425. doi:10.2304/rcie.2014.9.4.412

Simone, M., Askew, A., Lust, K., Eisenberg, M. E., \& Pisetsky, E. M. (2020). Disparities in selfreported eating disorders and academic impairment in sexual and gender minority college students relative to their heterosexual and cisgender peers. The International Journal of Eating Disorders, doi:10.1002/eat.23226

Singh, A. A., Richmond, K., \& Burnes, T. R. (2013). Feminist participatory action research with transgender communities: Fostering the practice of ethical and empowering research designs. International Journal of Transgenderism, 14, 93-104. doi:10.1080/ 15532739.2013 .818516

Smith, L. T. (1999). Decolonizing methodologies: Research and indigenous peoples. Zed Books.

Sky, I. (2016). Searching for my palm tree: Epistemological journeying of a child welfare doctoral student. Qualitative Social Work, 15 (5-6), 619-627.

Stanford, S., \& Lemberg, R. (2012). Measuring eating disorders in men: Development of the eating disorder assessment for men (EDAM). Eating Disorders, 20, 427-236. doi:10.1080/10640266.2012.715522

Stroumsa, D., Shires, D. A., Richardson, C. R., Jaffee, K. D., \& Woodford, M. R. (2019). Transphobia rather than education predicts provider knowledge of transgender health care. Medical Education, 53(4), 398-407. doi:10.1111/medu.13796

Sheena's Place. (n.d.). Retrieved November 16, 2019, from https://sheenasplace.org/

Tabaac, A., Perrin, P. B., \& Benotsch, E. G. (2018). Discrimination, mental health, and body image among transgender and gender-non-binary individuals: Constructing a multiple 
mediational path model. Journal of Gay \& Lesbian Social Services, 30(1), 1-16. doi:10.1080/10538720.2017.1408514

Taylor, S.R. [@sonyarenetaylor] (2020, June 15). If Black Trans Lives Don't Matter then No Ones Will. [Video] Instagram.https://www.instagram.com/tv/CBdCJ0ygXLp/?igshid= 1 gy $48 \mathrm{~km} 9 \mathrm{c} 9$ nux

T-FFED. (2020). About. Retrieved May 21, 2020, from https://www.facebook.com/pg/ TransFolxFightingEDs/about/?ref=page_internal

Toronto Trans Folx Eating Disorder Support Network. (2020). About. Retrieved May 21, 2020, from https://www.facebook.com/groups/232159864092148/about/

Tosh, J. (2017). Gender Non-conformity or Psychiatric Non-compliance? How organized noncompliance can offer a future without psychiatry. In M. Morrow and L.H. Malcoe (Eds.), Critical inquiries for social justice in mental health (pp. 255-282). University of Toronto Press.

Travers, R., Pyne, J., Bauer, G., Munro, L., Giambrone, B., Hammond, R., \& Scanlon, K. (2013). 'Community control' in CBPR: Challenges experienced and questions raised from the Trans PULSE project. Action Research, 11(4), 403-422. https://doi.org/10.1177/1476750313507093

Tebbe, E. A., \& Budge, S. L. (2016). Research with trans communities: Applying a processoriented approach to methodological considerations and research recommendations. The Counseling Psychologist, 44, 996-1024. doi:10.1177/0011000015609045

The Trevor Project (2018). Eating Disorders Among LGBTQ Youth: A 2018 National Assessment. Retreived from https://www.nationaleatingdisorders.org/sites/default/ 
files/nedaw18/NEDA\%20-Trevor\%20Project\%202018\%20Survey\%20\%20Full\%20Results.pdf

Travers, R., Pyne, J., Bauer, G., Munro, L., Giambrone, B., Hammond, R., \& Scanlon, K. (2013). 'Community control' in CBPR: Challenges experienced and questions raised from the Trans PULSE project. Action Research, 11(4), 403-422. https://doi.org/10.1177/1476750313507093

Tuck, E. \& Yang, K.W. (2012). Decolonization is not a Metaphor. Decolonization: Indigeneity, Education \& Society, 1(1), 1-40.

Wagaman, M. A., Obejero, R. C., \& Gregory, J. S. (2018). Countering the norm, (re)authoring our lives: The promise counterstorytelling holds as a research methodology with LGBTQ youth and beyond. International Journal of Qualitative Methods, 17(1), 160940691880064. doi:10.1177/1609406918800646

Wallerstein, N., \& Duran, B. (2017). The theoretical, historical and practice roots of CBPR. In N. Wallerstein, B. Duran, J.G. Oetzel \& M. Minkler (Eds.). Community-based participatory research for health: Advancing social and health equity, 17-29.

Watson, R. J., Adjei, J., Saewyc, E., Homma, Y., \& Goodenow, C. (2017). Trends and disparities in disordered eating among heterosexual and sexual minority adolescents: lgb eating disorders. International Journal of Eating Disorders, 50(1), 22-31. doi:10.1002/eat.2257

Watters, E. (2010, January 8). The Americanization of Mental Illness. The New York Times. https://www.nytimes.com/2010/01/10/magazine/10psyche-t.html

World Health Organization (2020). WHO/Europe brief-transgender health in the context of ICD-11. http://www.euro.who.int/en/health-topics/health-determinants/gender/genderdefinitions/whoeurope-brief-transgender-health-in-the-context-of-icd-11\#402872 
Yan, H., Ahmad, T., \& Kulkarni, A. (2015). Health Care for Transgender Patients: Medical Education and Patient Access. Canadian Federation of Medical Students. https://www.cfms.org/files/position-papers/2015\%20CFMS\%20Transgender\%20Health $\% 20$ Care.pdf

Zappa, A. (2017). Beyond erasure: The ethics of art therapy research with trans and genderindependent people. Art Therapy, 34(3), 129-134. https://doi.org/10.1080/07421656. 2017.1343074 